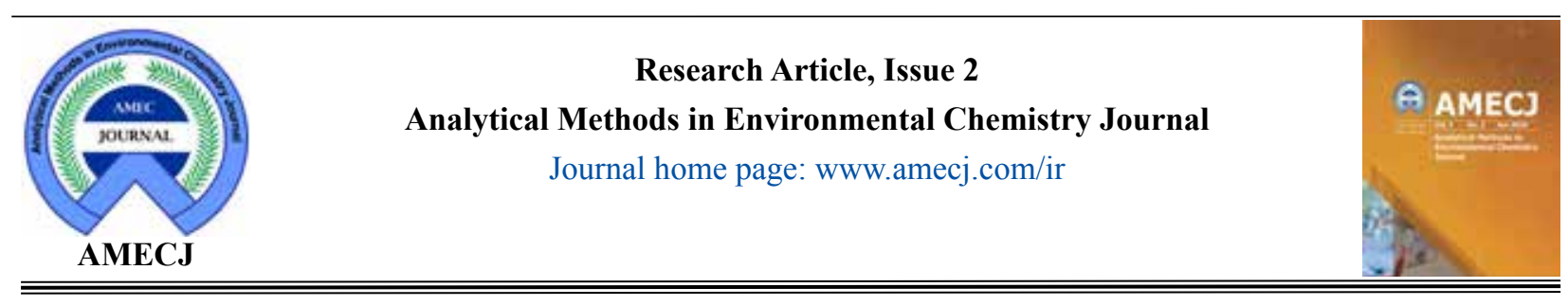

\title{
A Review, Methods for removal and adsorption of volatile organic compounds from environmental matrixes
}

\author{
Shahnaz Teimooria ${ }^{a}$, Amir Hessam Hassani ${ }^{\mathrm{b}, *}$ Mostafa Panahi $^{\mathrm{c}}$ and Nabiollah Mansouri ${ }^{\mathrm{d}}$ \\ ${ }^{a}$ PhD student of environmental engineering, Faculty of Natural Resources and Environment, \\ Science and Research Branch, Islamic Azad University, Tehran, Iran \\ ${ }^{b}$ Department of environmental engineering, Faculty of Natural Resources and Environment, \\ Science and Research Branch, Islamic Azad University, Tehran, Iran \\ ${ }^{c}$ Department of environmental engineering, Faculty of Natural Resources and Environment, \\ Science and Research Branch, Islamic Azad University, Tehran, Iran \\ ${ }^{d}$ Department of environmental engineering, Faculty of Natural Resources and Environment, \\ Science and Research Branch, Islamic Azad University, Tehran, Iran
}

\section{A R T I C L E I N F O :}

Received 6 Mar 2020

Revised form 5 May 2020

Accepted 30 May 2020

Available online 30 Jun 2020

Keywords:

Volatile organic compounds,

Chemistry and biochemistry method,

Removal,

Adsorption,

Water and air

\section{A B S T R A C T}

The volatile organic compounds (VOCs) have toxic effects on human health and environmental matrices. So, determination and removal of VOCs from the environmental samples such as water, wastewater and air are very important as they exert toxic effects on human. Many chemical techniques such as; analytical methods for sorbents (extraction, adsorption), sole gel method, pervaporation, regenerative catalytic oxidation (RCO), recuperative catalytic oxidation $(\mathrm{CO})$, adsorptive concentration-catalytic oxidation, photocatalytic oxidation (PCO), ozonation-catalytic oxidation and non-thermal plasma-catalytic oxidation, have been used for removal and reduction of VOCs from different matrices. This review study has been conducted to collect the adsorbents and applied chemistry methods which have been recently used in different works for the elimination of VOCs from air and water samples.

\section{Introduction}

Volatile organic compounds (VOCs) enter the environment through various sources, leaving severe environmental and health impacts [1]. The production of industrial wastewater is the main origin of VOCs which is considered as a negative aspect of industrial activity, exerting several adverse effects on the environment and human health [2-6]. Volatile organic compounds are one of the most widely used materials in the production of refrigerants, plastics, adhesives, paints, and petroleum products [3, 5, 7-12]. Benzene and toluene are regarded

\footnotetext{
* Corresponding Author: Amir Hessam Hassani

Email: ahh1346@gmail.com

https://doi.org/10.24200/amecj.v3.i02.100
}

as the most hazardous materials in the volatile organic compounds family and regarding their importance, a considerable amount of literature has been published on the issue of benzene and toluene potential adverse effects on health [1316]. According to the international agency for research on cancer [17], benzene is categorized as group 1 (carcinogenic to humans) and Toluene as group 2B (quietly carcinogenic to humans). What we know about the adverse effects of benzene and Toluene is largely based on previous studies which have proved that the common adverse effects of these organic compounds is neurotoxicity including drowsiness, headache, tremor, coma and dizziness [16, 18-20]. Benzene exposure has been reported to increase the risk of various cancers including leukemia and hematopoietic cancers 
$[15,21]$. It has been also recognized that benzene and Toluene affect skin, eyes and respiratory tract by inducing irritation [22-25]. Increased threatening impacts of VOCs increase health and environment concern and therefore, there is a crucial need to develop effective strategies to remove them. Several attempts have been made to eliminate or recover VOCs from wastewater; for example, distillation is commonly used, regardless of azeotropes formation or high energy consumption $[6,7,10,12,26-29]$. Hitherto, a number of approaches including adsorption [3032], condensation [33], incineration [34, 35] and thermal oxidation [36] have been established to eliminate VOCs from the environment. Treatment methods that have been established for VOCs removal are as follows: air stripping, adsorption, advance oxidation, distillation, anaerobic/aerobic biological treatment and the technology of membrane [27, 29, 37-42]. Many researchers have also applied pervaporation with nonporous membranes such as silicon rubbercoated PP to remove aromatic compounds from water sources [43-45]. Moreover, a large body of studies has taken the advantage of membranebased air stripping (MAS) process by the means of microporous hollow fiber contactors which is very effective in the treatment of aqueous effluents containing VOCs [46-56]. In the context of catalytic oxidation (one of the used techniques for VOCs removal), many researchers have focused on catalysts including noble metals (e.g. $\mathrm{Al}_{2} \mathrm{O}_{3}, \mathrm{TiO}_{2}, \mathrm{CeO}_{2}, \mathrm{MnOx}$ ), nonmetal oxides (e.g. $\mathrm{SiO}_{2}$ ), zeolites (e.g. ZSM, MCM, NaY) [57-62] and carbon derivatives $[63,64]$. However, metal oxides that are in charge of VOCs elimination are mostly derivatives of elements distributed in groups III-B through II-B of the periodic table such as $\mathrm{Ti}, \mathrm{Cu}, \mathrm{Mn}, \mathrm{Al}, \mathrm{Ce}, \mathrm{Co}, \mathrm{Fe}$ and so on [6567]. Despite extensive attempts toward VOCs removal, conducted technologies have, to some extent, shortcomings and limitations. This paper aims to review techniques used for VOCs removal and discuss their advantages/disadvantages and finally, focus on introduced solutions to improve the process of VOCs elimination.

\section{Data sources}

In this review, we used information such as journal articles, statistical data and conferences/ seminars papers as our data source. Surfing in scientific websites and databases including Google Scholar and Web of Science was a major way of accessing valuable information and related articles. Therefore, it was important to search at least one of related key words which are included in either titles or abstracts of papers and are as follows: "VOCs removal", "Catalytic oxidation", "Adsorbents" and "Nanomaterials". It was also crucial for papers to contain one or more of the aforementioned keywords to be embodied in this review.

\section{Experimental procedures and methods 3.1. Sorbent Methods}

The analytical methods for sorbents based on extraction and adsorption (chemical and physical) were used for VOCs removal from water and wastewater samples. Recently, the phenyl sulfonic acid (PhSA) modified carbon nanotubes (CNTs) were presented for benzene removal (BR) from waters. For separation process, the PhSA@CNTs based on the dispersive micro solid phase extraction method (D- $\mu$ SPE) was used for BR from water. The main mechanism was achieved by the polar $-\pi$ or $\pi-\pi$ electron donoracceptor interactions between the benzene and $\mathrm{SO} 3 \mathrm{H} / \mathrm{C} 6 \mathrm{H} 5$ group of CNTs surface (Fig. 1). According to the procedure, 10 mg of CNTs@ $\mathrm{PhSA}$ nanostructures was added to $5 \mathrm{~mL}$ of water samples with different benzene standard solution (0.1--10 $\left.\mathrm{mg} \mathrm{L}^{-1}\right)$ in GC vial. After shacking and centrifuging (3500rpm), the CNTs@PhSA sorbent separated from water samples and finally, its concentration was determined by static head space gas chromatography mass spectrometry (SHS-GC-MS) [68]. The mechanism based on CNTs@PhSO 3 was obtained with $\pi-\pi$ stacking between aromatic chain and $\mathrm{S}=\mathrm{O}$ bond of CNTs@PhSO 3 H (Fig. 2). 


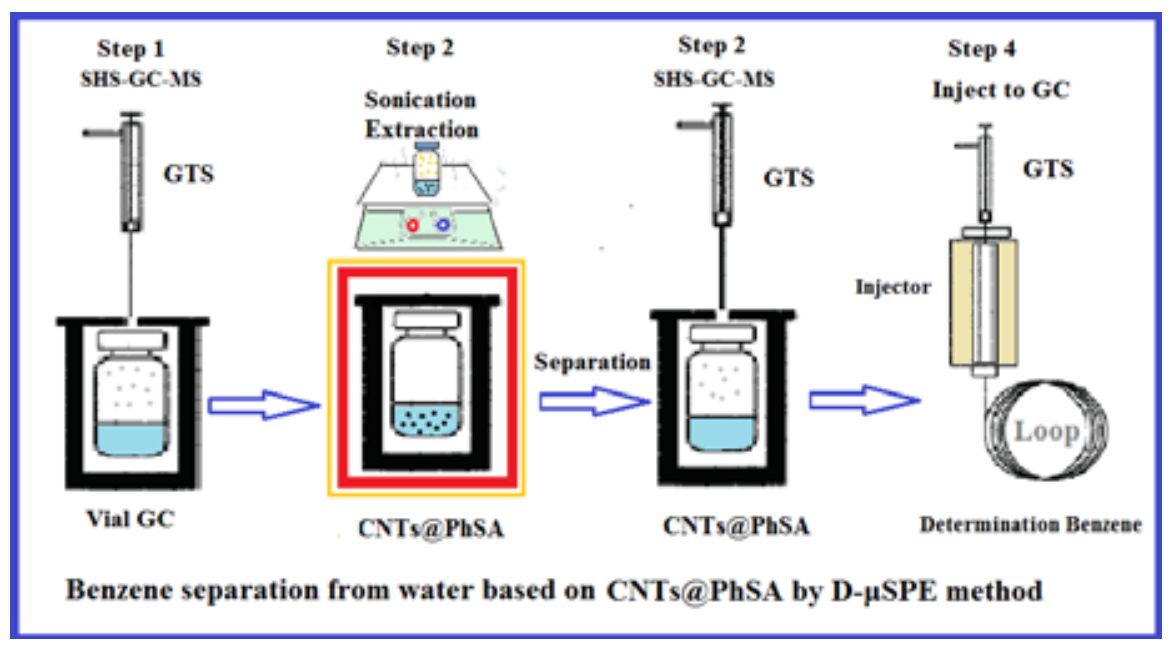

Fig. 1. Benzene extraction from waters based on CNTs@PhSA by D- $\mu$-SPE method

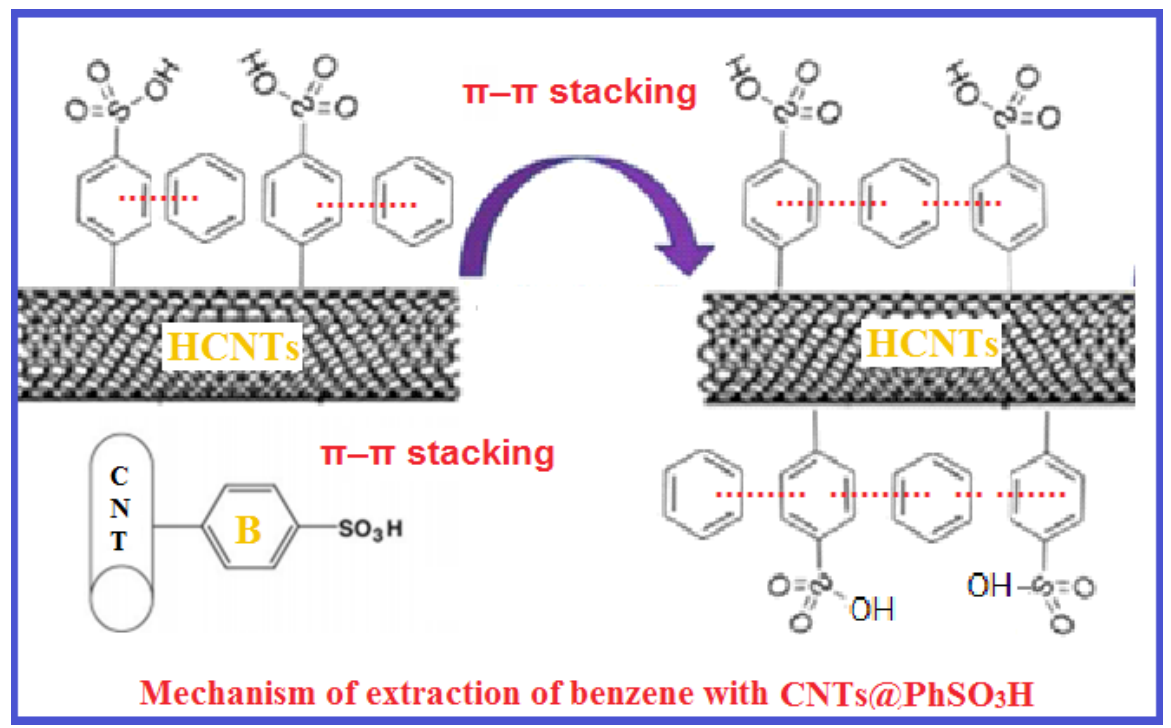

Fig. 2. Mechanism of extraction of benzene with CNTs@PhSO3H

The graphene based materials (GBMs) have been also used as a new technology in different fields of science specially in the environmental chemistry. The GBMs adsorbent was used for the removal of VOCs with high adsorption capacity and cost-effectivity through various functionalization processes on the surface. The intermolecular forces of GBMs with the gaseous pollutants caused gas adsorption. The strength of the interaction of GBMs with VOCs depended on surface area/properties, pore volume/size of the GBMs. The GBMs showed the excellent adsorption for the removal of VOCs. Among the different graphene structures, GO and rGO have mostly used for the VOC removal from waters [69]. The various models of the GO structures are shown in Figure 3 which was used for VOCs removal in different matrices. Hofmann and Holst first introduced graphite oxide and then Ruess et al designed a graphite oxide structure based on a wrinkled carbon sheet. Scholz and Boehm showed that the carbon sheet replaced by carbonyl and hydroxyl. Nakajima and Matsuo used two carbon layers linked to each other by $\mathrm{sp}_{3} \mathrm{CeC}$ bonds with carbonyl and hydroxyl groups. Lerf et al suggested a graphite oxide based on the unoxidized rings of benzene and that a wrinkled region of alicyclic 6- membered ring ethers is distributed randomly in a flat aromatic region. Szabó et al., showed a carbon network structure [70-73]. 


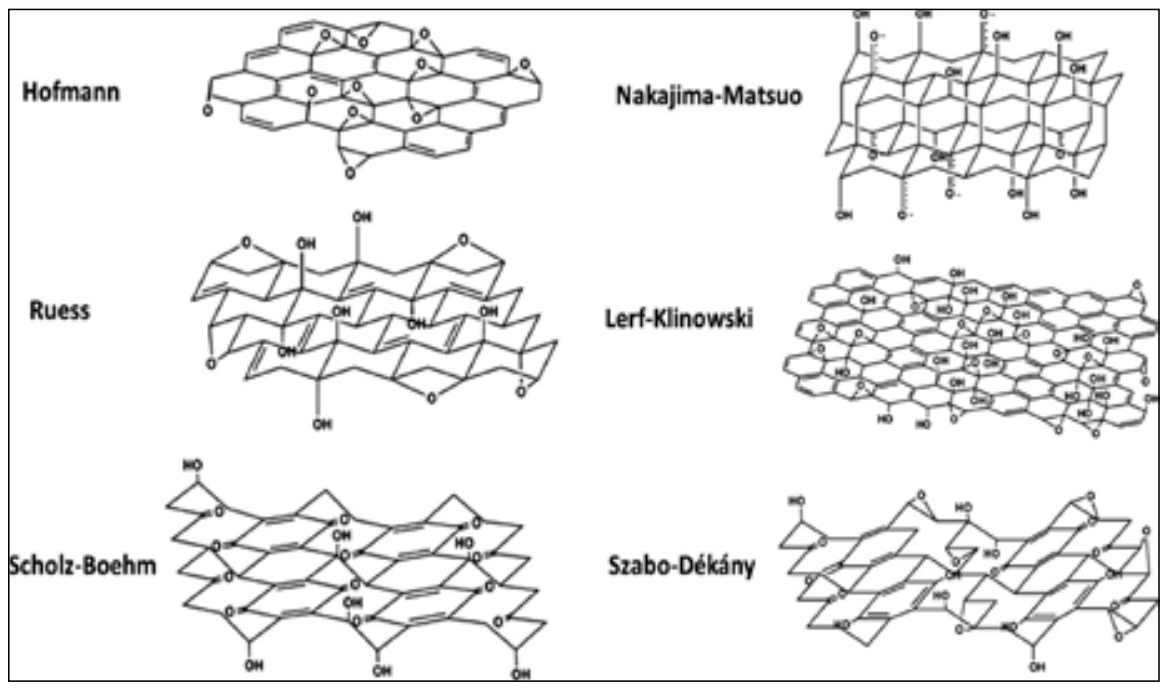

Fig. 3. Various models of the GO structure [70].

benzene, toluene, and xylene (BTX) are the major members of VOCs pollutions. These VOCs are preferably adsorbed on hydrophobic surfaces as compared to hydrophilic surfaces [74-75]. The previously results showed, the GO may exhibit less adsorption capacity for aromatic VOCs. Yu et al showed for $50 \mathrm{ppm}$ benzene, the adsorption capacities for $\mathrm{GO}$ and $\mathrm{rGO}$ were obtained 216.2 and $276.4 \mathrm{mg} \mathrm{g}^{-1}$, respectively. The rGO sorbent has a hydrophobic property with enhanced tendency ( $\pi-\pi$ bonds), increasing the adsorption capacity of VOCs relative to GO sorbents. In addition, the surface areas for rGO and GO were achieved $292.6 \mathrm{~m}^{2} \mathrm{~g}^{-1}$ and 236.4 $\mathrm{m}^{2} \mathrm{~g}^{-1}$, respectively and due to high surface area of $\mathrm{rGO}$, the adsorption capacity of VOCs was increased [69, 74, 75]. Szczęśniak et al showed that the high surface area of GBMs and GO caused to improve the benzene adsorption capacities for OMC. The incorporation of $\mathrm{GO}$ with $\mathrm{OMC} / \mathrm{KOH}$ increased the surface area from $740 \mathrm{~m}^{2} \mathrm{~g}^{-1}$ to $1370 \mathrm{~m}^{2} \mathrm{~g}^{-1}$. Also, the pore volume of $\mathrm{OMC}$ from 0.61 increased to $1.06 \mathrm{~cm}^{3} \mathrm{~g}^{-1}$ after the formation of $\mathrm{GO} / \mathrm{OMC}$. Finally, adsorption capacities for benzene were obtained $633 \mathrm{mg} \mathrm{g}^{-1}$ and $750 \mathrm{mg} \mathrm{g}^{-1}$ for OMC and GO/OMC, respectively [76-77]. GO - MOF5 was used for the removal of benzene vapor from air with capacity of $251 \mathrm{mg} \mathrm{g}^{-1}$ [78]. Due to high porosity of MOFs, they cannot retain small molecules under ambient conditions. So, the GO/MOF-5 composite was prepared using varying proportions of $\mathrm{GO}$, such as $1.75 \mathrm{wt} \%$, $3.5 \mathrm{wt} \%, 5.25 \mathrm{wt} \%$, and $7 \mathrm{wt} \%$ (Fig 4 ).

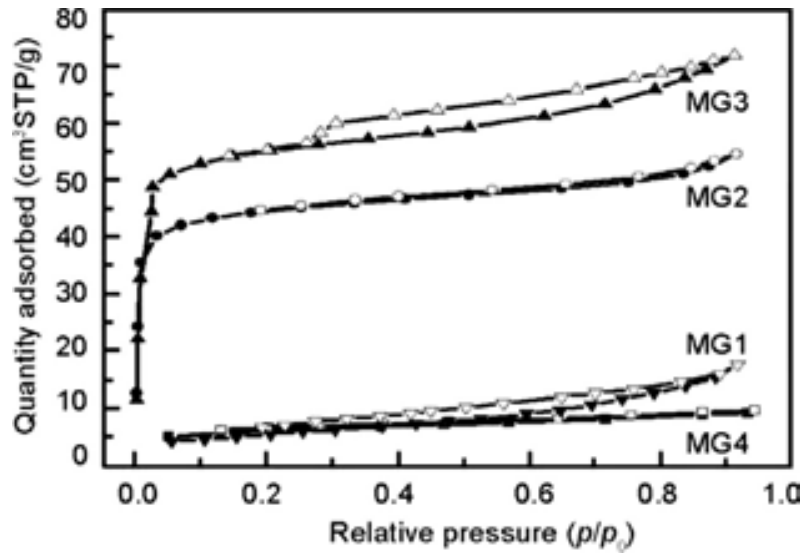

Fig. 4. Adsorption-desorption isotherms for graphene oxide/metal organic framework-5 (GO/MOF-5) for benzene [78]. MG (1-4) represents GO/MOF-5 composite with $1.75 \%, 3.5 \%, 5.25 \%$, and $7 \%$ of GO in MOF-5.

The GO and rGO was used for the removal of toluene by Kim et al. The $\pi-\pi$ bonds, hydrophobic and electrostatic interaction with toluene led to the absorption of toluene on $\mathrm{GO} / \mathrm{rGO}$ surfaces (Fig. 5). Different types of GBMs such as graphene platelets (GP), rGOMW, and $\mathrm{KOH}$ activated rGOMW (rGOMWKOH)) were analyzed for the toluene adsorption [79]. 


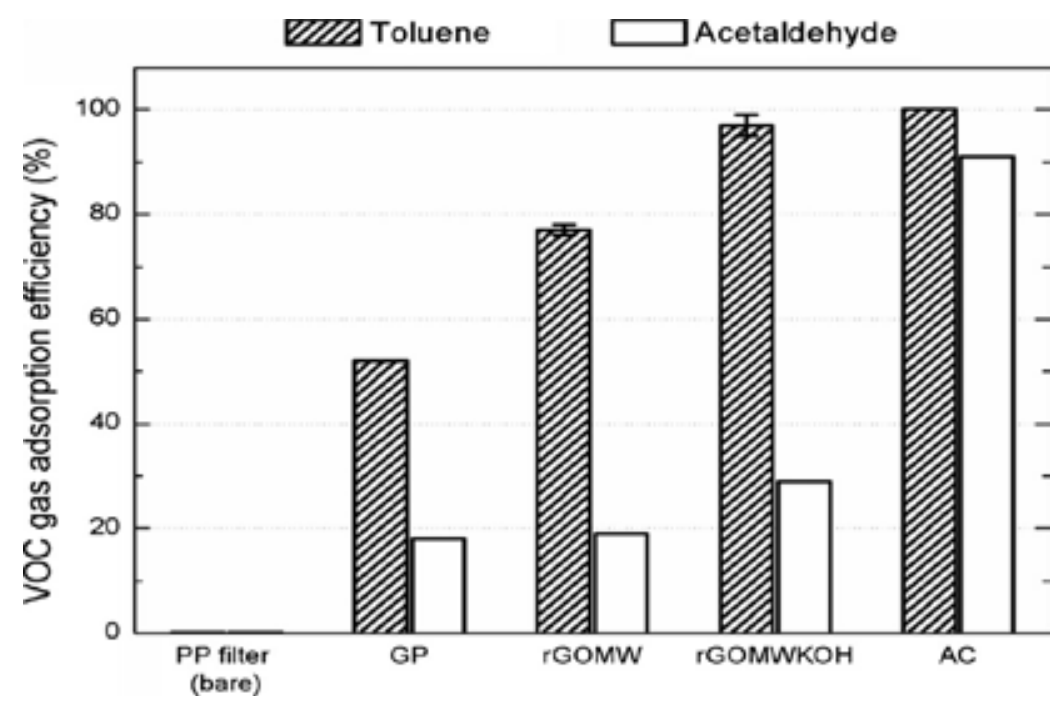

Fig. 5. Toluene and acetaldehyde removal capacity by rGOMWKOH compared to other adsorbents [81].

Aldehyde and ketone compounds are the most carbonyl VOCs which can be considered as sources of the environment contamination. GBMs can efficiently remove the carbonyl compounds from environment. For indoor formaldehyde removal, amino functionalized graphene sponge $(\mathrm{G} / \mathrm{S})$ or $\mathrm{G} / \mathrm{S}$ decorated with graphene nanodots (G-GND/S) were used by $\mathrm{Wu}$ et al. G-GND/S with high amine groups on surface as compared to G/S caused a high interaction with formaldehyde molecules (Fig 6). The results showed that the adsorption capacity of GGND/S and G/S were achieved $22.8 \mathrm{mg} / \mathrm{g}^{-1}$ and $7.5 \mathrm{mg} / \mathrm{g}^{-1}$ for formaldehyde, respectively [80].

Lim et al. prepared mesoporous-structured graphene powder through the method of thermal expansion (Fig. 7) and used them as adsorbents for removing VOCs. According to Figure 8 the characteristics and morphology of the prepared adsorbent was defined through different methods including scanning electron microscopy (SEM), X-ray photoelectron spectroscopy and $\mathrm{N}_{2}$ isotherms. Adsorption

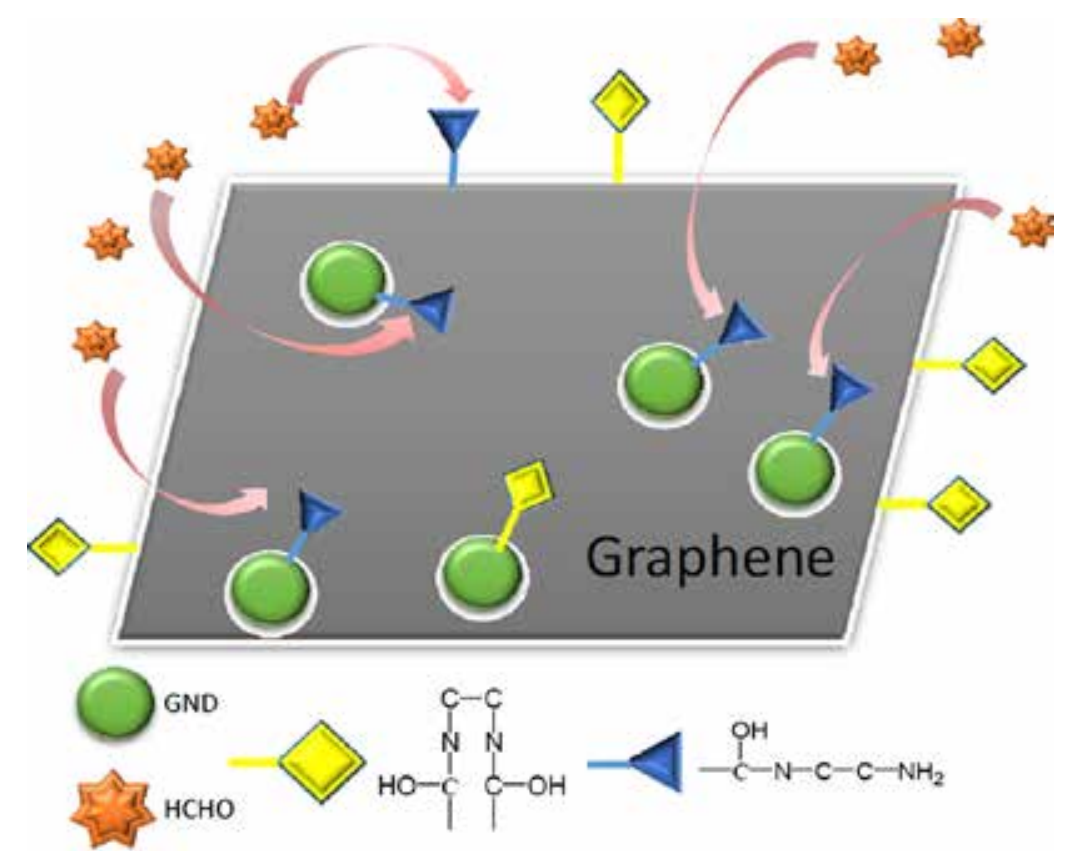

Fig. 6. Interaction of amino graphene nanodots decorated functionalized graphene sponge with formaldehyde molecules 


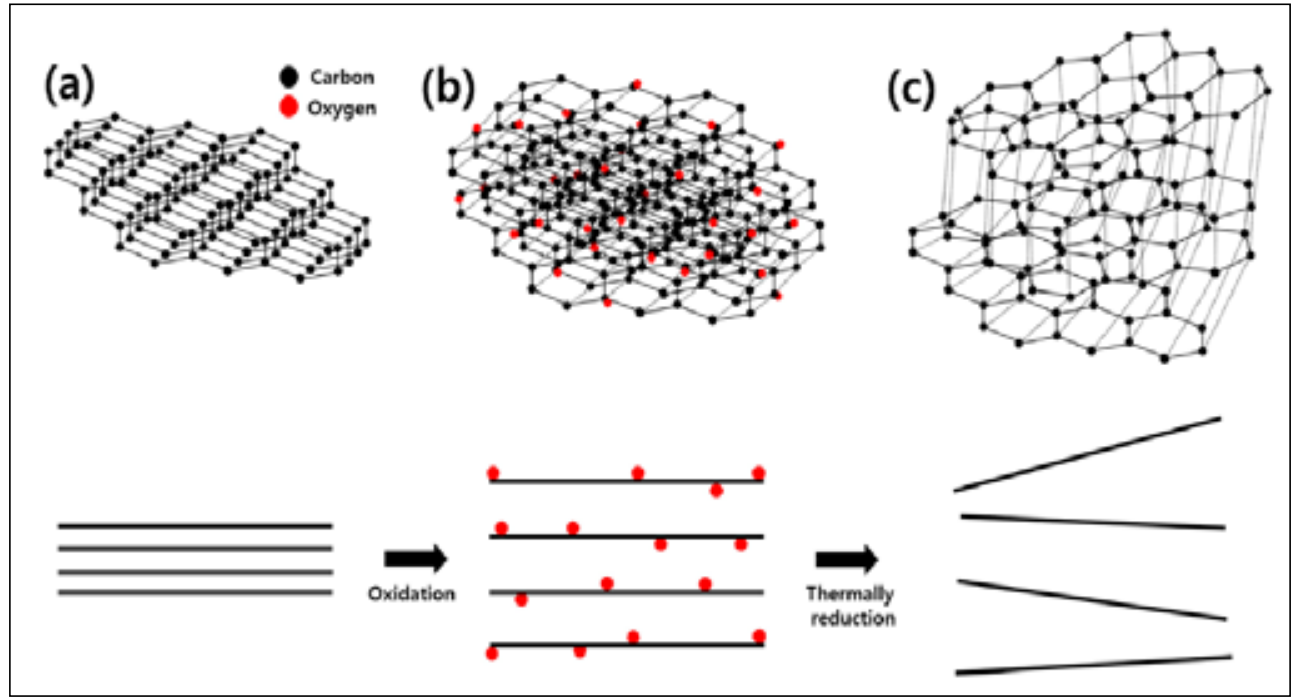

Fig. 7. The scheme of thermal expansion mechanism; a: graphite powder b: GO powder c: TEGP [82].

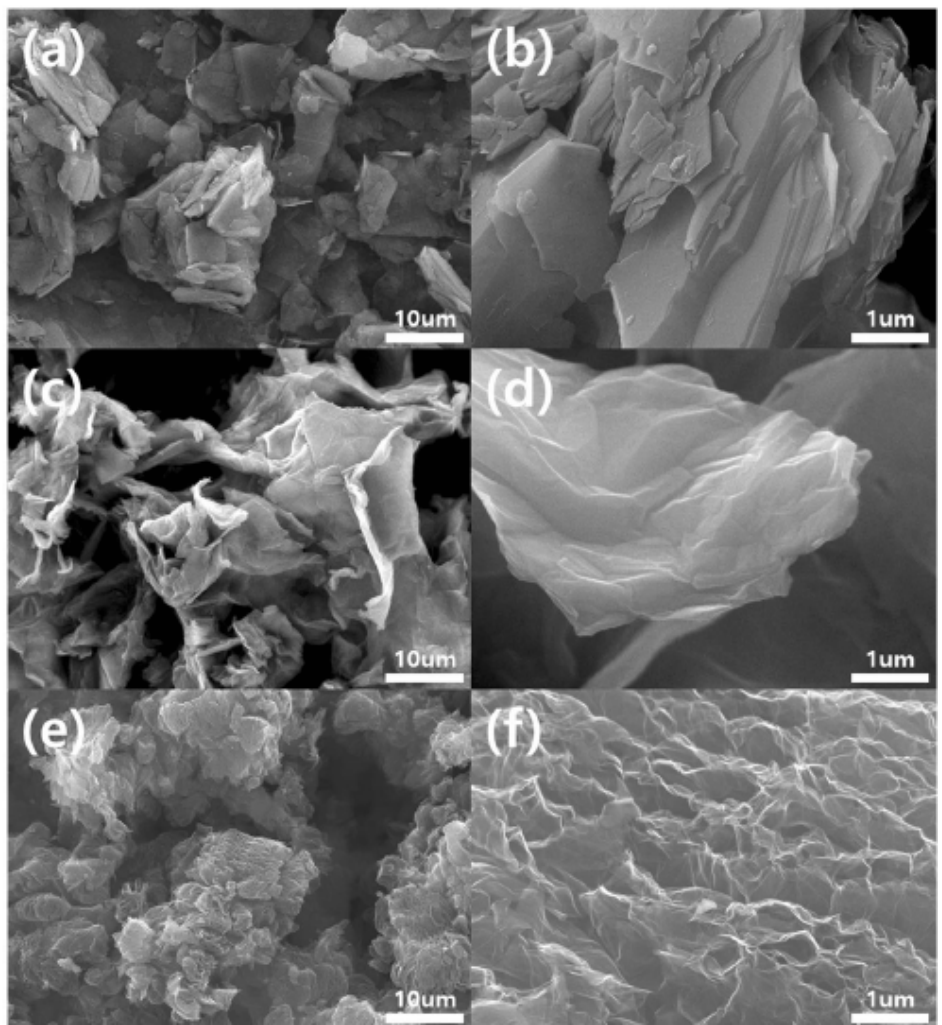

Fig. 8. SEM images of graphite powder $(a, b)$, graphite oxide (GO) $(\mathrm{c}, \mathrm{d})$ and TEGP $(\mathrm{e}, \mathrm{f})[82]$.

capacity of graphene powder was examined using propylene filter, at a concentration range of VOCs $(30,50,100 \mathrm{ppm})$. The results of the study indicated that thermal expanded graphene powder (TEGP) is an effective material for VOCs removal which acts in a proper chemical oxidation using heat energy. It was also reported that TEGP is of economical materials, due to its reusability [82].

\subsection{Sole Gel Method}

The sole-gel process is a method for producing solid materials from small molecules. As a chemicalwet technique, recently, it has been widely used in the fields of material sciences and ceramic engineering. This kind of methods are employed 
primarily for the synthesis of materials (mostly metal oxides) starting with a chemical solution that acts as a precursor for an integrated nexus of both segregated particle and network polymer [83].

Metal alkoxides and metal chlorides, which are considered as frequent precursors, undergo different forms of hydrolysis and poly-condensation reactions. Binding of metal centers with either oxo (M-O-M) or hydroxo (M-OH-M) bridges leads to the formation of metal oxides and generates metal-oxo or metal-hydroxo polymers in solution. Therefore, the sol involves in the formation of a gel-like diphasic system containing both solid and liquid with segregated particles to a continues polymer structure morphologies [83].

The sole-gel method has been increasingly applied for the development of various materials including material for catalysis [84, 85], chemical sensors [86, 87], optical gain media [88], solid state electrochemical devices [88], photochromic and non-linear applications [90-92], membranes [93] and fibers [94]. One of the intriguing applications of the sole-gel technology is photo catalyst preparation. Photo catalysts have been widely used to degenerate VOCs. Common photo catalysts are semiconductors like $\mathrm{ZnO}, \mathrm{GaP}, \mathrm{TiO}_{2}, \mathrm{SiC}, \mathrm{CdS}$ and $\mathrm{Fe}_{2} \mathrm{O}_{3}$ [95]. Among these photo catalysts, $\mathrm{TiO}_{2}$ is the most applicable photo catalyst in the context of eliminating environmental pollutants because of its chemical stability, high oxidizing potential, low cost, non-toxicity and environmentally friendly properties [96-99]. Parvizi et al. in their study about perovskite nano-catalysts, synthesized a series of La1-x Ax $\mathrm{MnO}_{3}$ (A: Co, Zn, Mg, Ba) through sol-gel method (Fig. 9) and then evaluated the performance of these catalysts in the elimination process of BTX compounds. After conducting the research, the FTIR results showed that all characteristics related to efficient catalyst was present in synthesized catalyst, indicating acceptable outcomes of sol-gel method [100]. By applying nonhydrolytic sol-gel method, Debecker et al. synthesized $\mathrm{V}_{2} \mathrm{O}_{5}-\mathrm{TiO}_{2}$ and added $\mathrm{Mo}$ and $\mathrm{W}$ oxides to promote the catalysis performance of catalyst (Fig. 10). The results of the research indicated a significantly better oxidation performance (93\% oxidation) and a highly efficient action for $\mathrm{CO}_{2}$ selectivity for the purpose of VOCs removal [101]. These results imply the importance of sol-gel method in the process of efficient catalyst synthesis.

Sarafraz Yazdi et al. developed a novel fiber

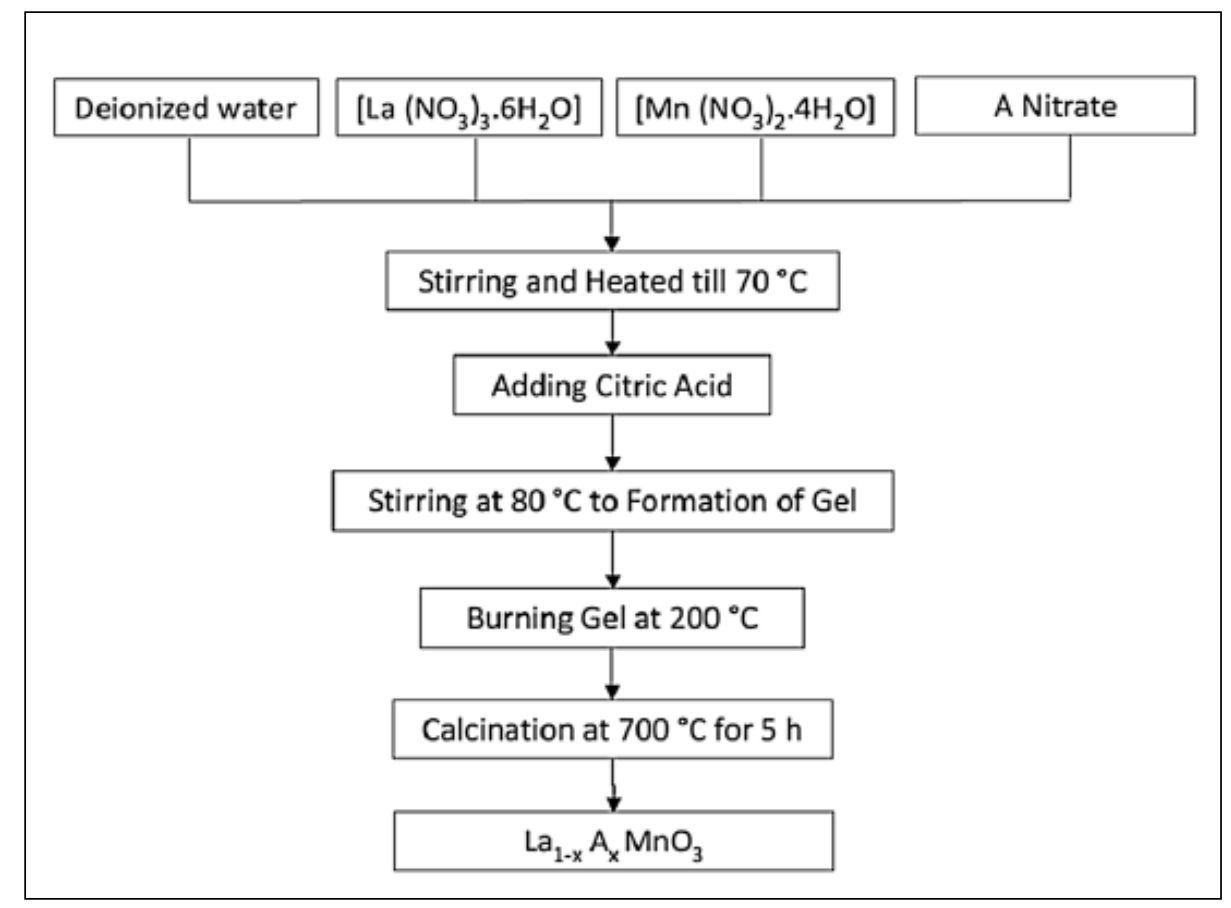

Fig 9. Schematic procedure of La1-x Ax MnO3 (A: Co, $\mathrm{Zn}, \mathrm{Mg}, \mathrm{Ba}$ ) perovskite nanocatalyst preparation by sol-gel method [100]. 
to improve the elimination of trace amounts of BTEX. At first, poly ethylene glycol (PEG) grafted on multi-walled carbon nanotubes (PEGg-MWCNTs) undergone a chemical bonding with sol-gel to produce the unique fiber, as shown in Figure 11. The results showed that the porous structure, thermal stability, potent selectivity and durability of mentioned fiber lead to a remarkably better performance in the route of removing BTEX. Also, due to porous structure of sol-gel coating, the surface area of fiber, extraction velocity, steps of desorption and capacity of sample loading increase significantly [102].

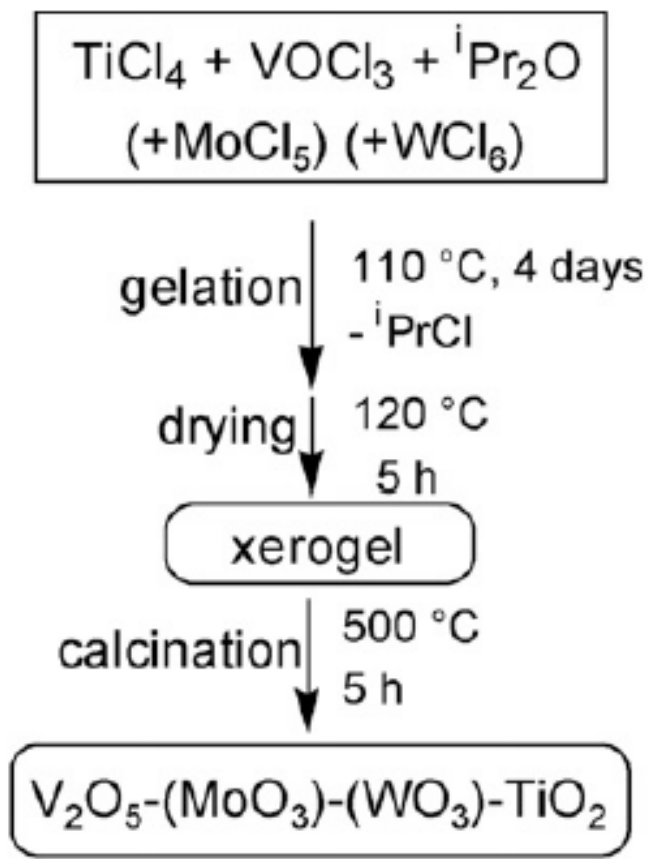

Fig. 10. Nonhydrolytic sol-gel preparation method [101]

\subsection{Pervaporation}

Membrane-based pervaporation (PV) technology serves as an economical and alternative technique in the organic-organic separation processes. A number of researchers have reported the elimination of VOCs from water sources which has been achieved through various polymeric membranes, using pervaporation technology [103111]. Uragami et.al prepared a PVC membrane (hydrophobic polymeric membrane) and used an ionic liquid (1-allyl-3-butylimidazolium bis (trifluoromethane sulfonyl) imid ([ABIM]TFIS)) with a remarkable and low affinity for VOCs and water, respectively. Through the process of PV, Uragami and coworkers evaluated the performance of prepared [ABIM] [TFIS] /PVC aqueous solutions of dilute benzene and reported that the combination of PVC membranes with [ABIM] [TFIS] ionic liquid represents higher permeability and benzene/water selectivity in a concentration dependent manner. As shown in Figure 12, it was also revealed that incorporation of PDMS component decreases the density of membrane and induces benzene permeability [112]. Kujawa et al. functionalized and increased the hydrophobicity of two types of ceramic membranes with molecular sizes of $5 \mathrm{kDa}$ and $300 \mathrm{kDa}$ (Fig. 13). They reported that membranes with increased hydrophobicity can efficiently remove VOCs from binary aqueous solutions through vacuum membrane distillation procedure [113].

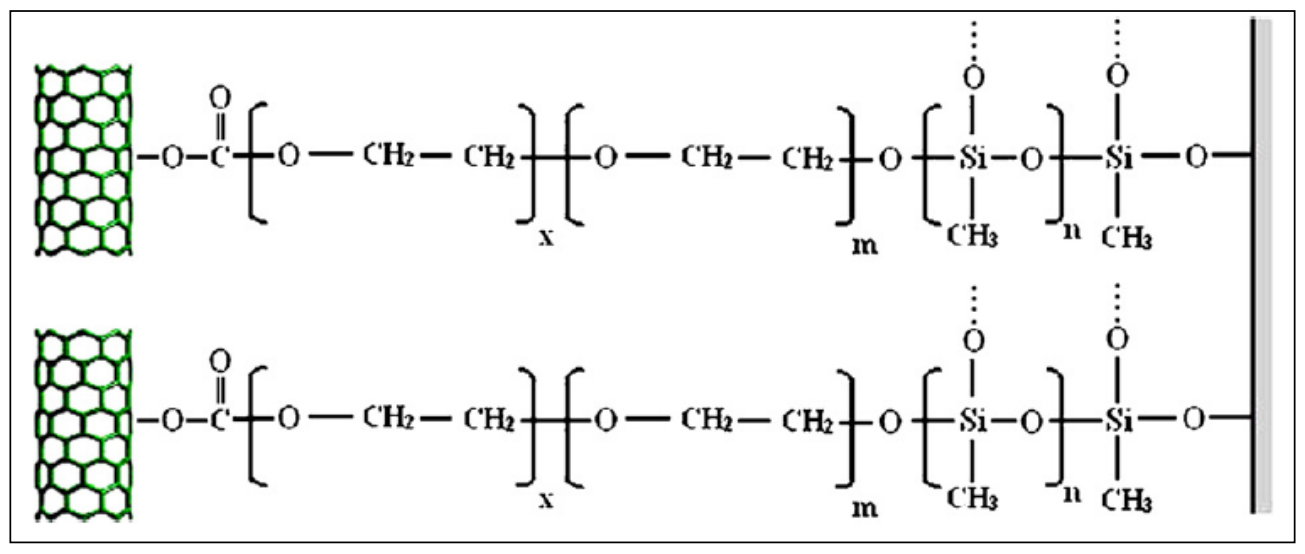

Fig. 11. Sol-gel PEG-g-MWCNTs coating [102] 


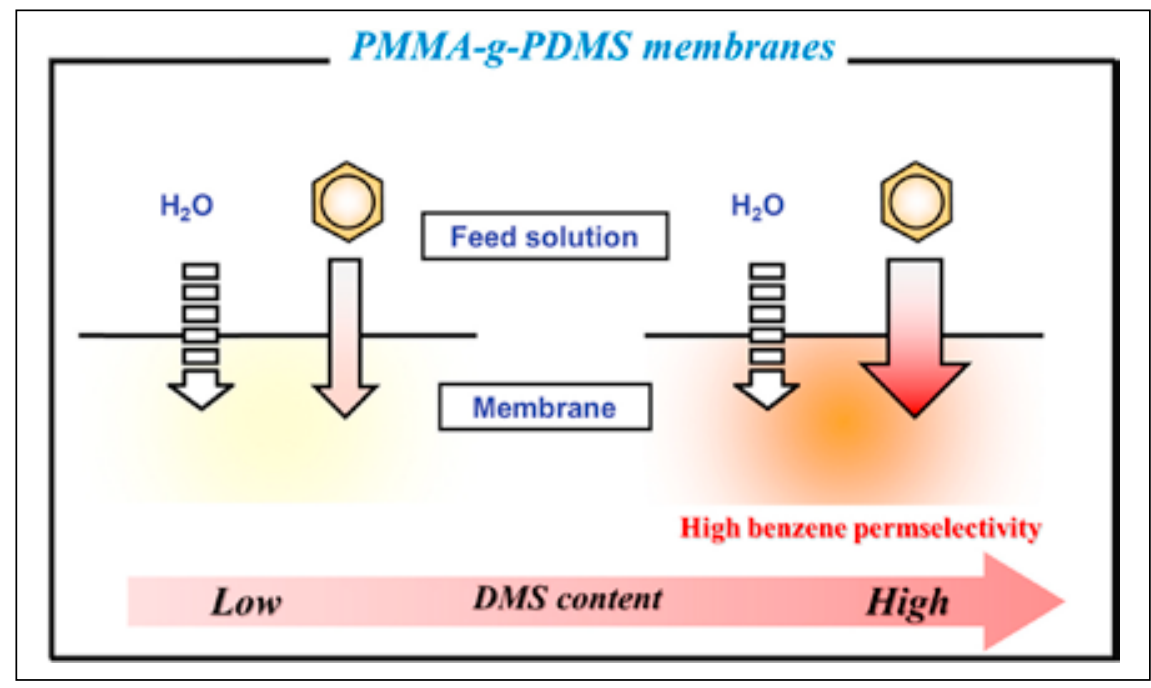

Fig. 12. The illustration of benzene permselectivity and benzene permeability under the effect of PMMA-PDMS membranes [112].

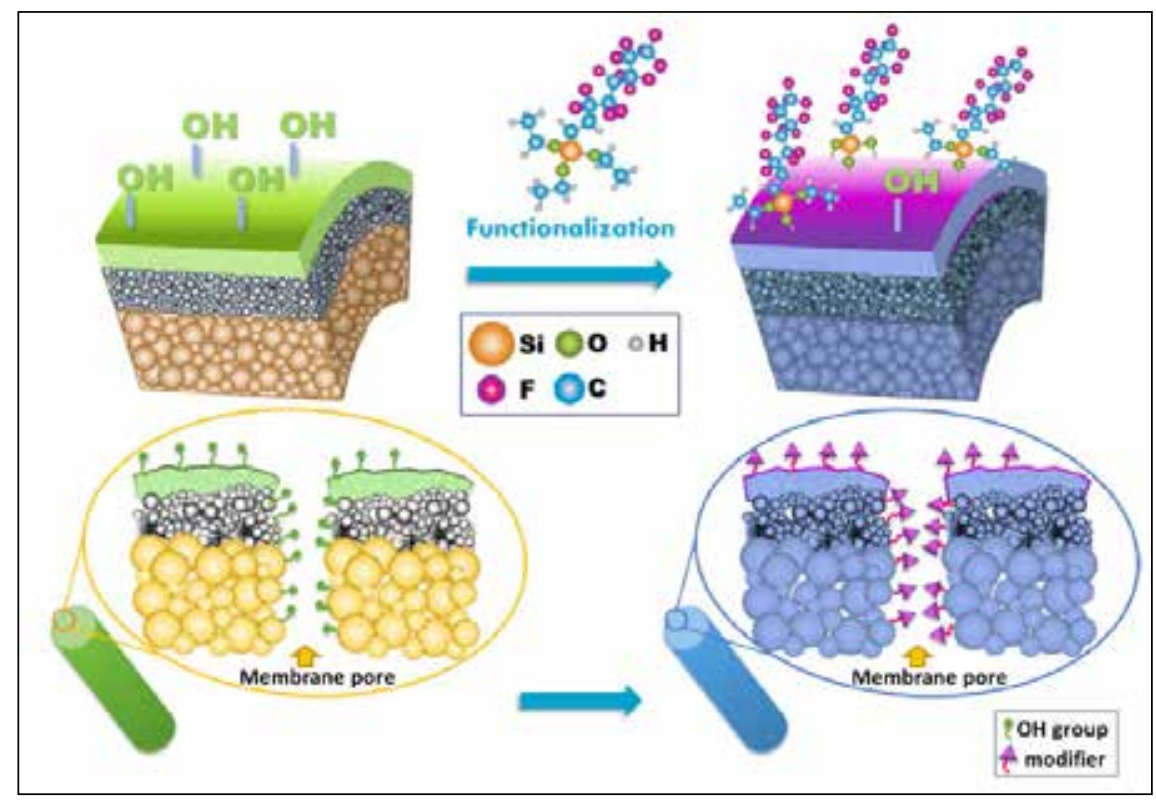

Fig. 13. Ceramic membrane's functionalization by perfluoroalkylsilanes [113].

\subsection{Catalytic oxidation}

\subsubsection{Regenerative catalytic oxidation (RCO)}

In parallel with the regenerative thermal oxidation (RTO), RCO is one of the most energy-saving techniques, being as relatively similar working mechanism as RTO. These techniques contain two or more beds with random or structured ceramic packs which are of high specific heat materials (800$1000 \mathrm{~J} \mathrm{Kg}^{-1} \mathrm{~K}^{-1}$ ) and perform as heat transfer media. As shown in Figure 14, frequently used two bed RCO usually contains ceramic layer, catalyst layer, natural gas burner or electrical heater which plays a role as heat storage, reaction media and heat supply, respectively. Due to its relatively lower price, natural gas is preferred to use rather than electrical heating. The mechanism of VOCs removal in this technique involves passage of VOCs flow from ceramics cabinet A which preheats VOCs, followed by a temperature increase up to $200-300{ }^{\circ} \mathrm{K}$. When heater keeps the flow temperature of catalyst (i.e., TChamber) higher than the light-off temperature (TC), effective degradation of VOCs occurs. Simultaneously, the releasing heat from VOCs oxidation contributes to Tchamber and even can 
serve as a usable heat. In the next step, reacted flow goes down and its heat reserves as a high specific heat, preheating the inlet VOCs flow in the next cabinet B to A cycle. Thermal Recovery Efficiency $(\eta)$ is a factor evaluating energy-efficiency related properties of oxidizing equipment. Although the $\eta$ of RTO is up to $90 \%$, the $\eta$ of RCO can reach $95 \%$ or higher [114]. Liu et al. designed a formula of $\mathrm{Ru}-5 \mathrm{M} / \mathrm{TiO}_{2}$ (M: $\mathrm{Mn}, \mathrm{Co}, \mathrm{Ce}, \mathrm{Cu}, \mathrm{Fe}$ ) for ruthenium-based bimetallic catalyst and examined its effect on benzene oxidation efficiency. After deep examination of different bimetallic species, it was proved that the combination of $\mathrm{Ru}-$ $5 \mathrm{Co} / \mathrm{TiO}_{2}$ can be the most effective species for the process of benzene removal. Figure 15 Illustrates the represented mechanism of benzene removal, using combined $\mathrm{Ru}-5 \mathrm{Co} /$ $\mathrm{TiO}_{2}$ catalyst [115]. In the study of Zhang et al., nano-crystalline copper-manganese oxides were prepared using sol-gel method. The relativity between $\mathrm{Cu}$ and $\mathrm{Mn}$ was defined as $\mathrm{Cu} 3 \mathrm{x}-\mathrm{Mnx}$ ( $\mathrm{x}$ can be equal to 0 , $1,1.5,2,2.5,3$ and is a representation of molar ratio of $\mathrm{Cu}$ and $\mathrm{Mn}$ ); the optimal ratio was also found to be 2. Results showed that $\mathrm{CuMn}_{2}$ with the spinel structure of $\mathrm{CuMn}_{2} \mathrm{O}_{4}$ exhibits a larger surface area, smaller pore size and network oxygen species, leading to enhanced catalytic activity of $\mathrm{CuMn}_{2}$ which can be the result of stabilized $\mathrm{CuMn}_{2} \mathrm{O}_{4}$ active sites and synergistic effect between $\mathrm{Cu}$ and Mn (Fig. 16) [116].

\subsubsection{Recuperative catalytic oxidation (CO)}

Recuperative catalytic oxidation (CO), known as a simplified version of RCO, is a technique consisting of tubular or plate heat exchanger instead of regenerative thermal ceramic layers in RCO. In this technique, at first, a heat exchanger preheats VOCs flow, causing a temperature increase by about $50-200^{\circ} \mathrm{K}$. Then, the next heater further heats the flow up to the light-off temperature of catalyst (usually above
$573 \mathrm{~K})$. Finally, reinforcement of VOCs oxidation occurs to produce $\mathrm{CO}_{2}$ and $\mathrm{H}_{2} \mathrm{O}$ with a significant amount of heat release. The $\eta$ of a normal $\mathrm{CO}$ is generally lower than $70 \%$, indicating that the costumer should cost more than usual to obtain required energy for keeping the equipment to work

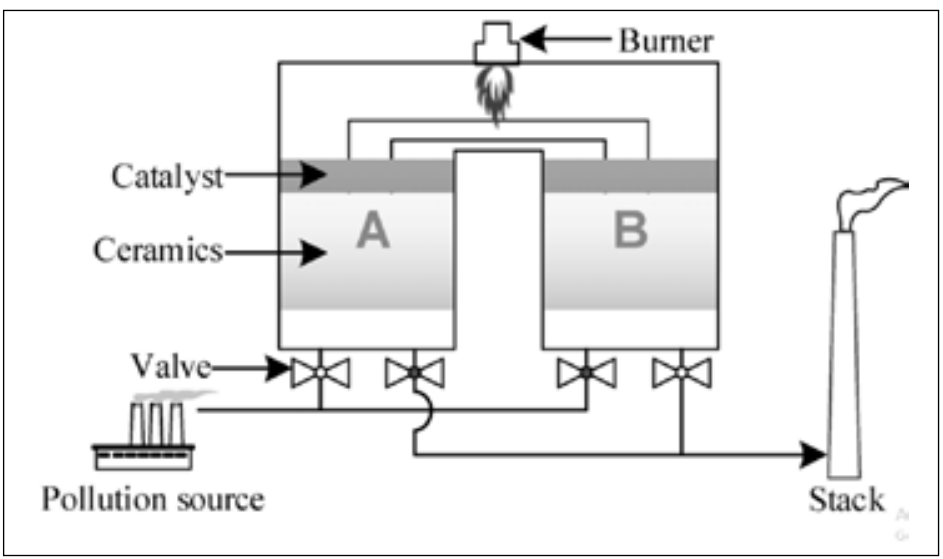

Fig. 14. The schematic diagram of regenerative catalytic oxidizer [114].

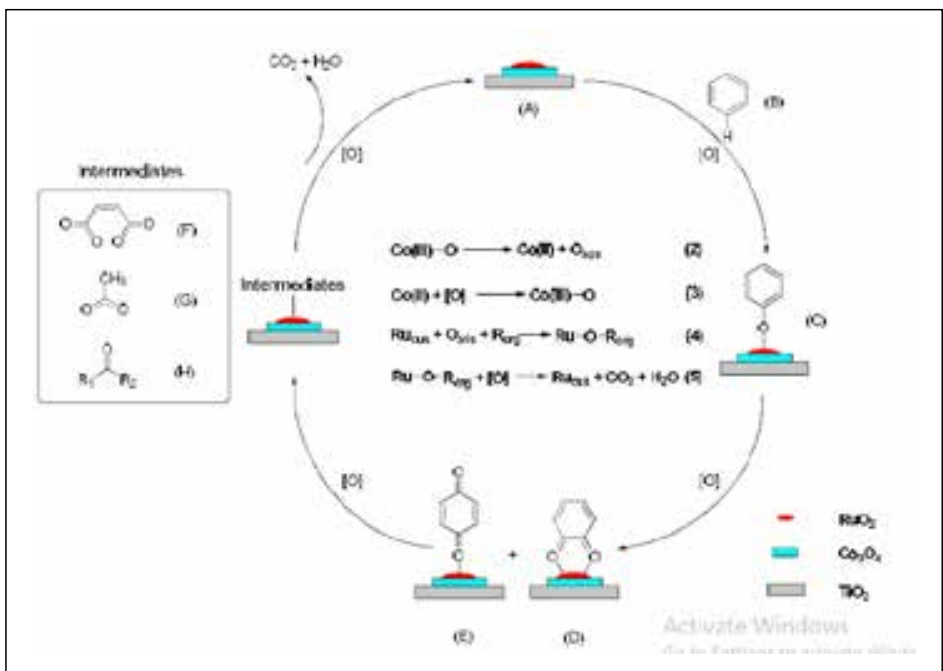

Fig. 15. Presented mechanism of the effect of $\mathrm{Ru}-5 \mathrm{Co} / \mathrm{TiO}_{2}$ on the benzene oxidation [115].

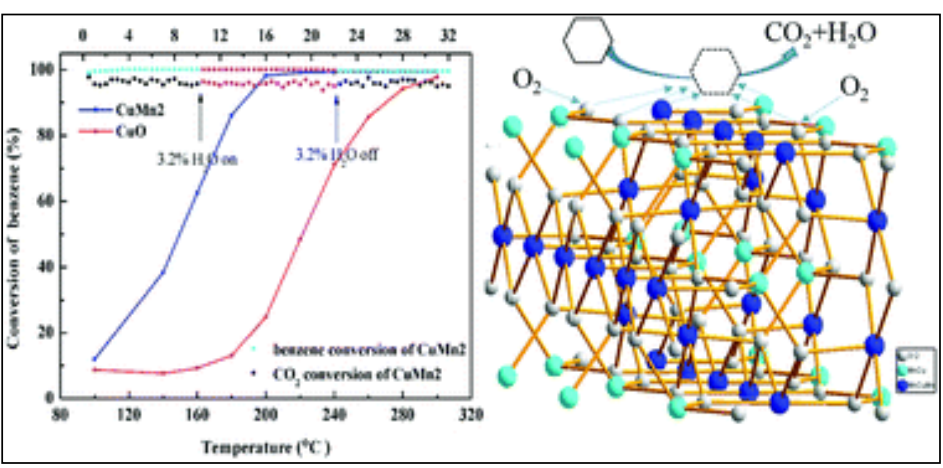

Fig. 16. The sample of $\mathrm{CuMn}_{2}$ and relative spinel structure [116]. 


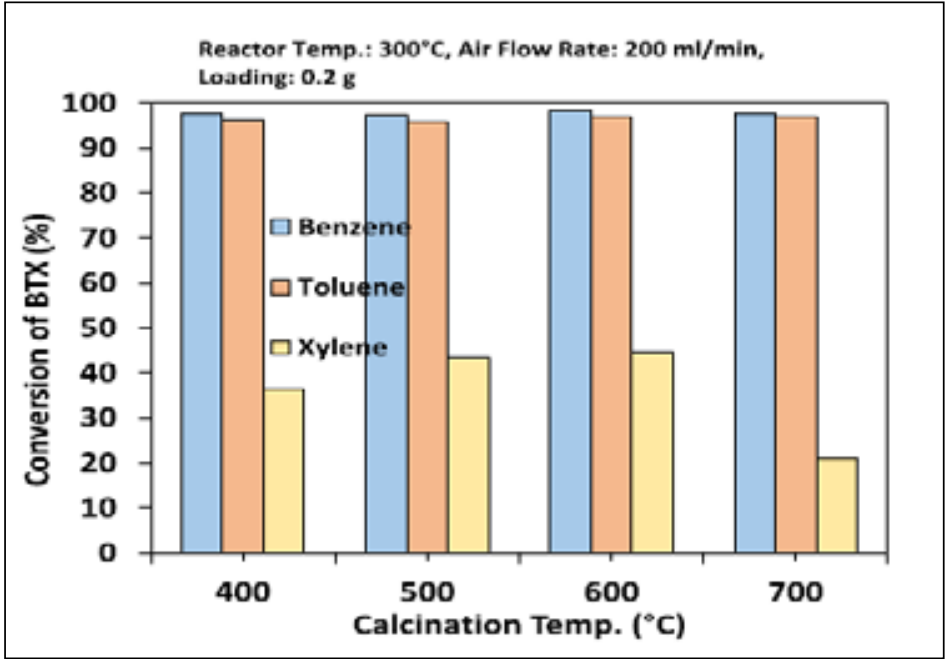

Fig. 17. The effect of manganese oxide calcination temperature on the thermal oxidation of BTX [118].

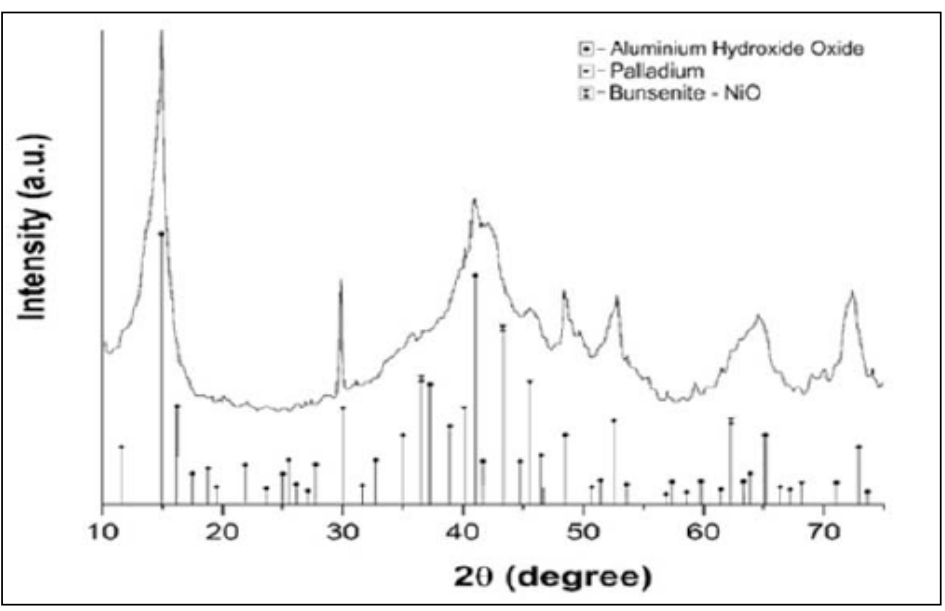

Fig. 18. The XRD pattern of the Ni/Pd/AlOOH [119].

on VOCs elimination. In fact, $\mathrm{CO}$ can't be effective for large-scale and low concentrations of VOCs pollutant removal [117]. However, considering low initial investment and high flexibility, the technique of $\mathrm{CO}$ can be effective for samples with small flowrate $\left(<5000 \mathrm{~m}^{3} \mathrm{~h}^{-1}\right)$ of VOCs pollutant [114]. Intriguingly, it is important to note that in the case of large-volume and low concentration VOCs emissions, there is an advanced technology named adsorptive concentration-catalytic oxidation which makes it possible to remove such VOCs samples. Hoseini and coworkers aimed to synthesize manganese oxide and impregnate it into different loadings of alumina. They utilized the resulted material in the procedure of BTX oxidation followed by performance analysis. Findings of the study represented the most effective morphology and higher surface area at $10 \%$ of alumina loading. Further evaluation highlighted that the best condition for oxidation is $10 \mathrm{kV}, 0.2$ $\mathrm{g} \mathrm{Mn10Al}$ in the $200 \mathrm{~mL} \mathrm{~min}^{-1}$ flowrate of pollutant with resulting oxidation of 97 , 99 and $74 \%$ benzene, toluene and xylene, respectively. The catalytic activity of catalyst was investigated by catalyst calcination at four different temperatures $(400,500,600$, $700{ }^{\circ} \mathrm{C}$ ). As Figure 17 it can be seen that the highest level of BTX conversion was found to be in Mn600 catalyst [118]. Georgiev in 2019 investigated ozone-assisted catalytic oxidation of benzene through alumina, silica and boehmite-supported $\mathrm{Ni} / \mathrm{Pd}$ catalysts in $353 \mathrm{~K}$. Three bimetallic Ni/Pd samples in a nano scale were synthesized with loadings of $4.7 \% \mathrm{Ni}, 0.17 \% \mathrm{Pd}$ supported on $\mathrm{SiO}_{2}$, $\mathrm{AlOOH}$ and $\mathrm{Al}_{2} \mathrm{O}_{3}$ and by the means of extractive-pyrolytic method. According to the results of the study, the highest steadystate activity of catalysts was attributed to $\mathrm{Ni} / \mathrm{Pd} / \mathrm{AlOOH}$ catalyst (Fig. 18). Georgiev reported that this activity is dependent on the amount of ozone decomposition capacity of catalysts which leads to oxidative species production; a sample with a high ozone decomposition ability (related to surface area of support) is capable of benzene oxidation in a high extent [119].

\subsubsection{Photocatalytic oxidation (PCO)}

As a different and distinguishable technology, photocatalytic oxidation has received considerable attention, due to its mild reaction condition and non-selectivity. By using UV or visible light in the environment temperature, photocatalytic oxidation works different from thermal catalysis; therefore, compared to $\mathrm{RCO}$ and $\mathrm{CO}$, the configuration of PCO is simpler (Fig. 19). Photocatalysis has a wide variety of activities regarding various VOCs at the environment temperature, however, due 
to low quantum efficiency and long residence time requirement, it has a limited oxidizing power and load adaptability [114]. Zhang et al. [120] introduced a new modified photocatalyst named $\mathrm{TiO}_{2}-\mathrm{UiO}-66-\mathrm{NH}_{2}$ (constituting from the combination of $\mathrm{TiO}_{2}$ and $\mathrm{UiO}-66-\mathrm{NH}_{2}$ ) and reported that the new photocatalyst can significantly improve photocatalytic performance for VOCs oxidation (Fig. 20). According to this study, the $\mathrm{TiO}_{2}$-UN photocatalytic system, represented good $\mathrm{CO}_{2}$ selectivity and high photocatalytic activity with $72.70 \%$ of toluene decomposition during 240 min of reaction, which was even higher than single $\mathrm{TiO}_{2}(44.22 \%)$ and $\mathrm{UiO}-66-\mathrm{NH}_{2}(7.48 \%)$. In the study of benzene removal by the means of
PCO technology, Ji $\mathrm{J}$ et al proposed that VUVPCO technique (Fig. 21) is significantly effective in comparison with the ordinary UV-PCO [121]. In contrast to UV-PCO in which benzene degradation is only attributed to photocatalytic oxidation, VUVPCO technique consists of several decomposition pathways alongside VUV photolysis and PCO. Benzene degradation hardly occurs under the effect of UV irradiation [122], however, VUV irradiation have a benzene removal efficiency of about 48radiation potency in the process of benzene degradation is related to the formation of hydroxyl radicals ( $\mathrm{Y} O H)$ and oxygen species such as $\mathrm{O}(1 \mathrm{D})$, $\mathrm{O}(3 \mathrm{P})$ and $\mathrm{O}_{3}[123]$.

\subsection{Ozonation-catalytic oxidation}

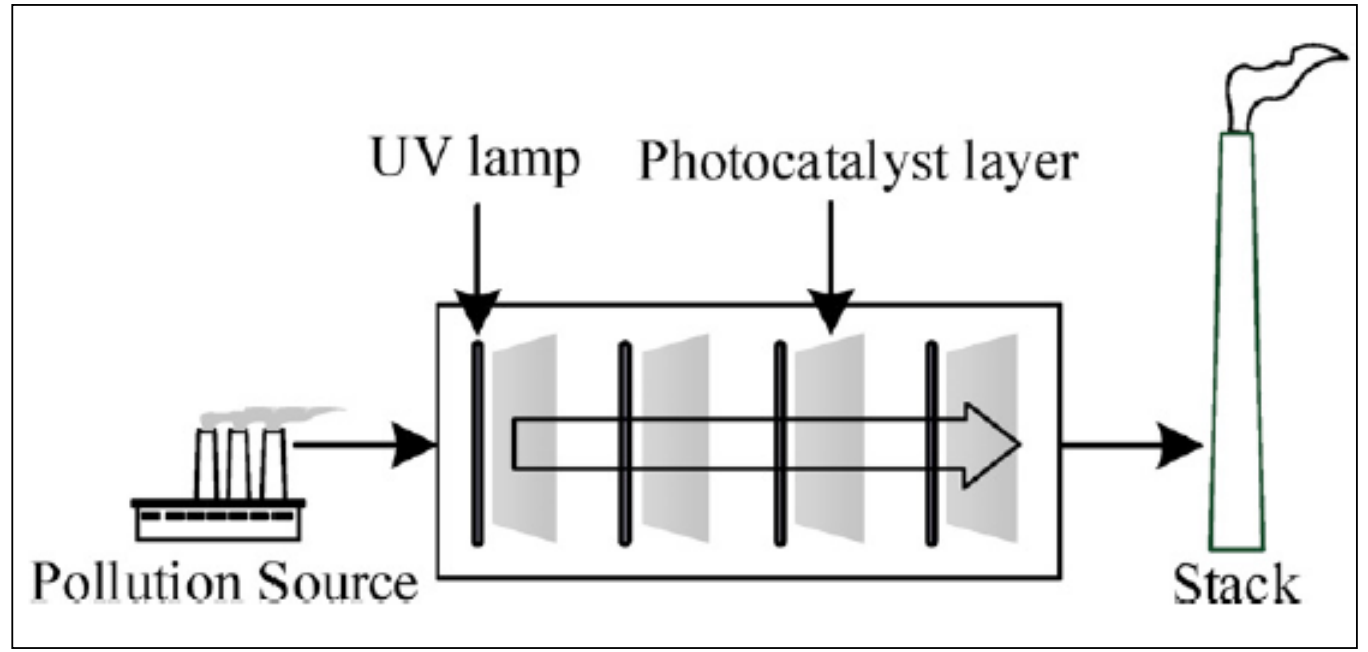

Fig. 19. Schematic configuration of PCO [114].

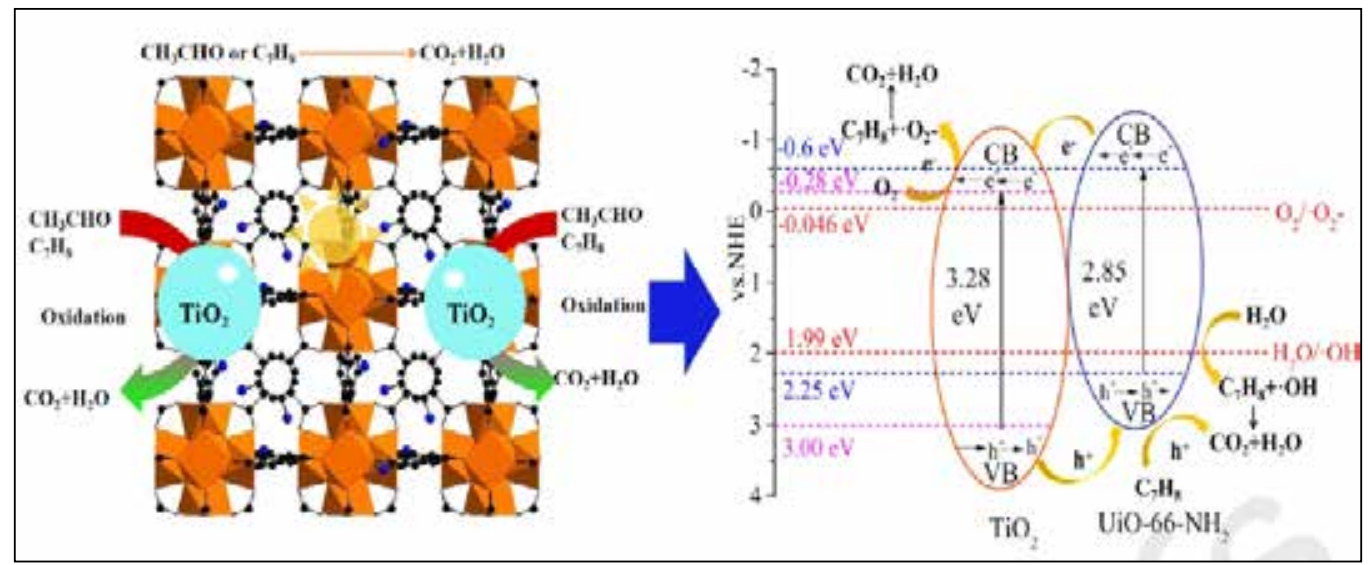

Fig. 20. Hypothesized pathways for photocatalytic oxidation of VOCs by TiO2-UiO-66- $\mathrm{NH}_{2}$ [120]. 


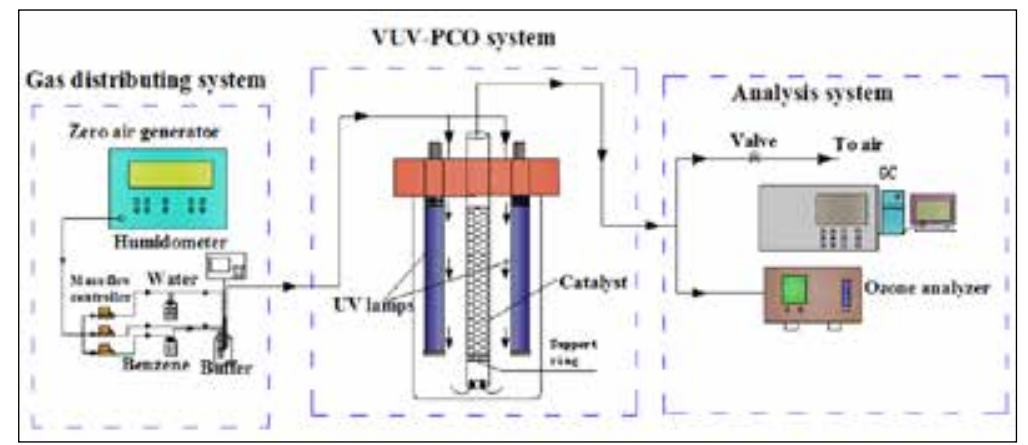

Fig. 21. The schematic diagram of VUV-PCO system [121].

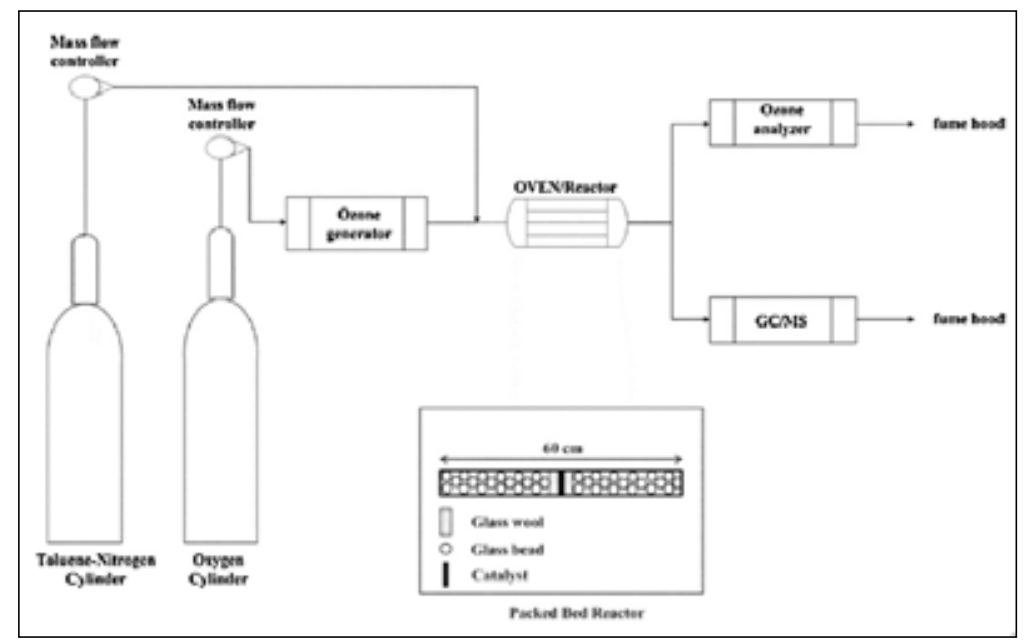

Fig. 22. The scheam of experimental procedure [126].

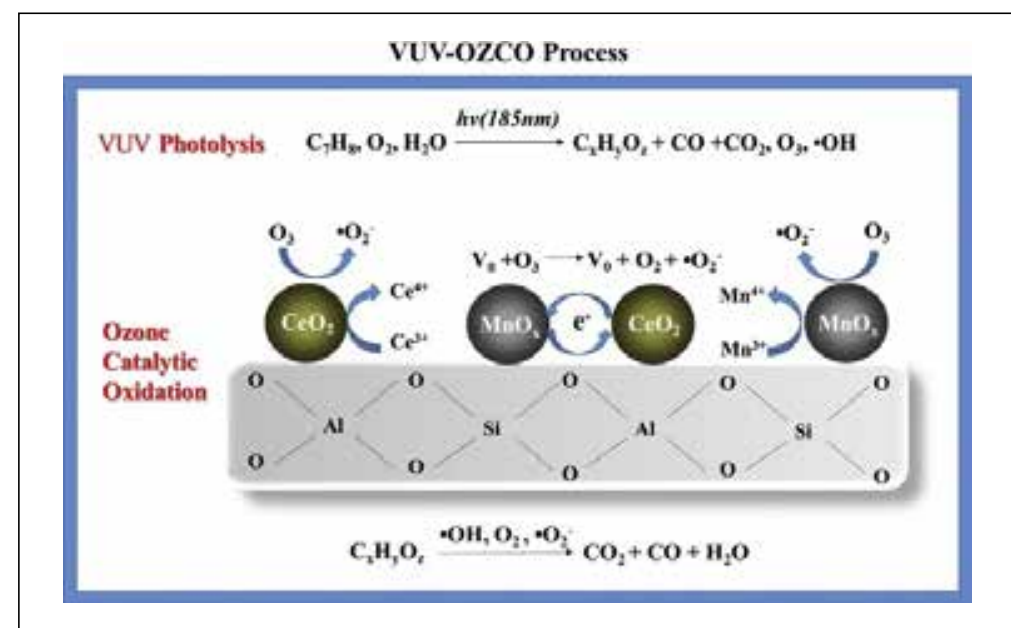

Fig. 23. VUV-OZCO process [125].

oxidation has been extensively applied in water sterilization and wastewater treatment procedures. Since ozone isn't very stable in gas environment, as a single technique, it can't be so effective in the oxidation of VOCs to $\mathrm{CO}_{2}$ and $\mathrm{H}_{2} \mathrm{O}$. However, ozone oxidation has the capability of being used as a pre-treatment step before common catalytic techniques (e.g. thermal catalysis and photocatalysis) and promotes a synergistic effect alongside these technologies. Rezaei et al. in their 2013 study indicated that transition metal oxide-based catalysts propose efficient VOCs removal by catalytic ozonation, obviating the need for costly noble metals which are frequently used in the VOCs catalytic combustion with oxygen. The mentioned study investigated different loadings of $\mathrm{Mn}$ in a temperature range and reported that increased temperature leads to better activity of catalyst and lower loadings of Mn resulting in surged and efficient toluene oxidation (analyzed by GC-MASS) and ensuing ozone decomposition (measured by ozone analyzer) (Fig. 22) [124]. Shu et al. designed a novel process which was a combination of VUV photolysis and $\mathrm{O}_{3}$ catalytic oxidation (VUVOZCO). In this system, VOCs are firstly destructed by VUV and then are oxidized through VUV-generated $\mathrm{O}_{3}$ in the presence of catalyst. $\mathrm{O}_{3}$ by-product is also eliminated simultaneously. In the study of Shu et al. it was revealed that the novel Mn-xCe-ZSM-5 catalyst

In the technology of ozonation-catalytic oxidation, Ozone $\left(\mathrm{O}_{3}\right)$, a strong oxidant with a standard redox potential at $2.07 \mathrm{eV}$, is used. Water sterilization and wastewater treatment procedures have extensively taken the advantages of ozone oxidation. Ozone along with VUV-OZCO system (Fig. 23) can have the capacity to simultaneously decompose $\mathrm{O}_{3}$ byproduct and improve toluene removal efficiency [125].

\subsection{Non-thermal plasma-catalytic oxidation}


Non-thermal plasma (NTP) which has been introduced as green technology for elimination of VOCs from indoor and industrial gas streams, is a superior source of chemically active species $\left(\mathrm{OH}\right.$ and $\mathrm{O}^{2-}$ radicals, ions, excited species, etc). This property leads non-thermal plasma to provide a highly reactive environment (caused by electron's acceleration, dissociation and ionization); without any energy consumption on heating the entire gas stream, in which reactive species oxidize various VOCs molecules and consequently degrade them. Besides low energy efficiency and inferior $\mathrm{CO}_{2}$ selectivity, a major difficulty with non-thermal plasma is production of by-products including NOX, $\mathrm{O}_{3}$ and other intermediates relating to the fact that electrons do not have enough energy to mineralize BTX molecules [127]. Thus, nonthermal plasma oxidation can't be considered as a single technique to deal with VOCs pollution, because products of uncompleted reactions in this technique can act as secondary pollutions on their own.

Agreat solution for the aforementioned problem is combining the non-thermal plasma oxidation with catalysis (Fig. 24). This combination has been extensively investigated during the last decade, indicating that the system of non-thermal plasma-catalysis is obviously capable of improving energy efficiency and suppressing unwanted by-products in the process of VOCs degradation [128]. Non-

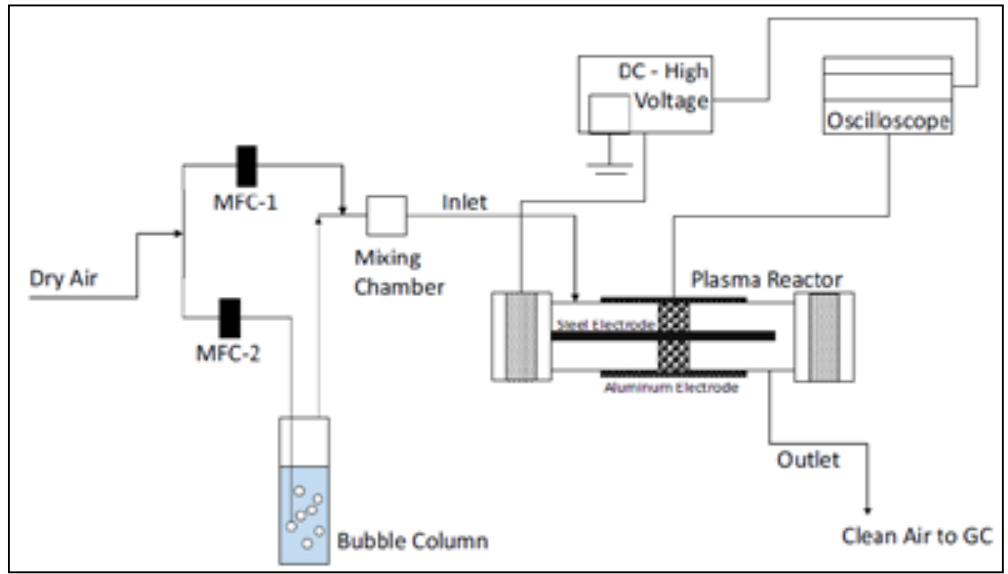

Fig. 24. Experimental setup of hybrid plasma-catalytic system for oxidation of VOCs [115].

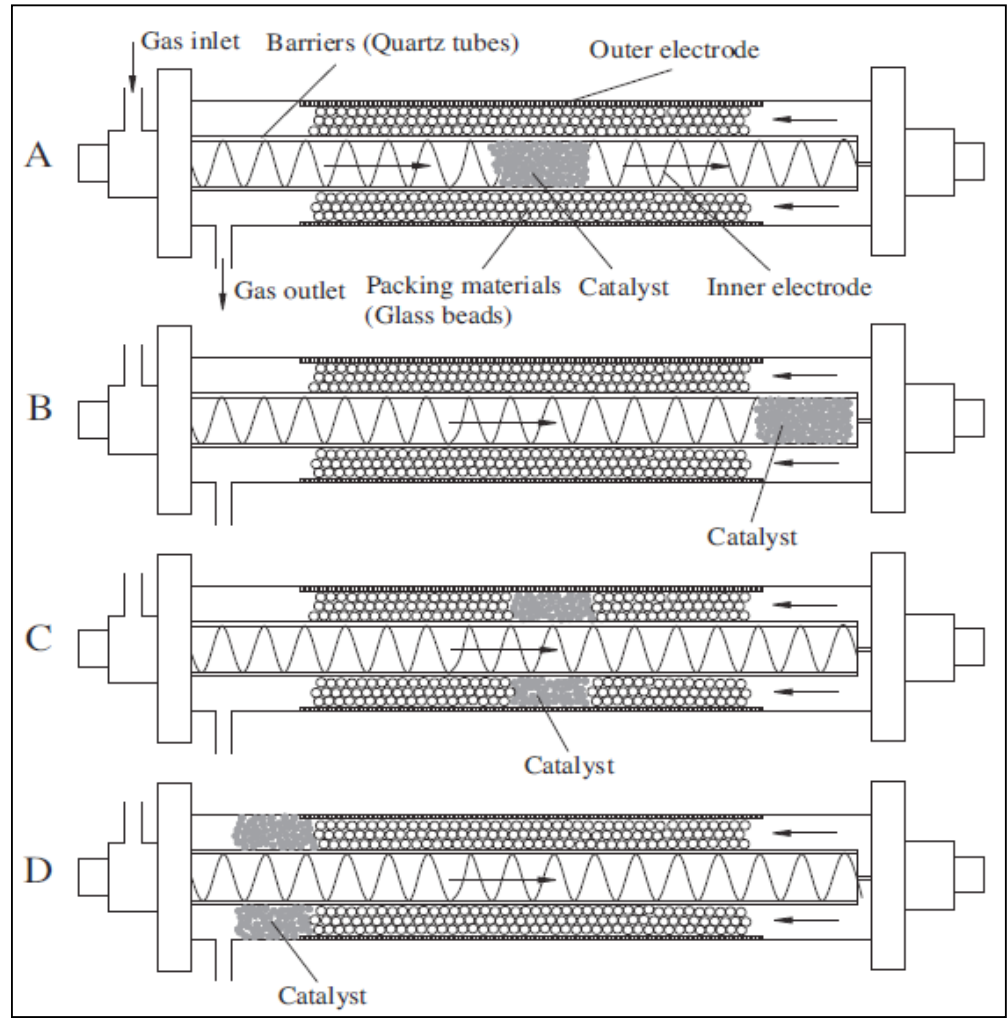

Fig. 25. Different plasma-catalysis systems in IPC and PPC configurations: (a) catalysts in the region I, (b) catalysts in the downstream of region I, (c) catalysts in the region II, (d) catalysts in the downstream of region II [130].

that this combination can significantly improve benzene removal efficiency and promote $\mathrm{CO}_{2}$ formation, with a simultaneously suppression of $\mathrm{CO}$ [129].

In the study of Jiang et al. both IPC and PPC catalyst in the elimination of benzene and showed 
configurations of NTP (Fig. 25) constituted from a hybrid surface/packed bed discharge (HSPBD) with different catalysts including Agx Ce1-x/y$\mathrm{Al}_{2} \mathrm{O}_{3}$ was applied. From the result of the study, it was revealed that through the plasma-catalysis system and present of $\mathrm{Agx} \mathrm{Ce} 1-\mathrm{x} / \mathrm{y}-\mathrm{Al}_{2} \mathrm{O}_{3}$ catalyst significantly enhance benzene degradation and improve COx selectivity. The study of Jiang also showed that the PPC process has a better effect on the decomposition of $\mathrm{O}_{3}$ and benzene [130].

\subsection{Nanotechnology}

Nanotechnology is an increasingly important area of the recent technology, playing a cardinal role in a bunch of fields. Among the various subtypes of this technology, carbon nanotubes (CNTs) has attracted a great deal of interest in the context of industrial applications and implementations. As shown in Figure 26 and based on the number of the structure layers, CNTs are classified as single walled carbon nanotubes (SWCNTs) and multi walled carbon nanotubes (MWCNTs).

Pourfayaz et al. evaluated the adsorption capacity of two types of multi walled carbon nanotubes

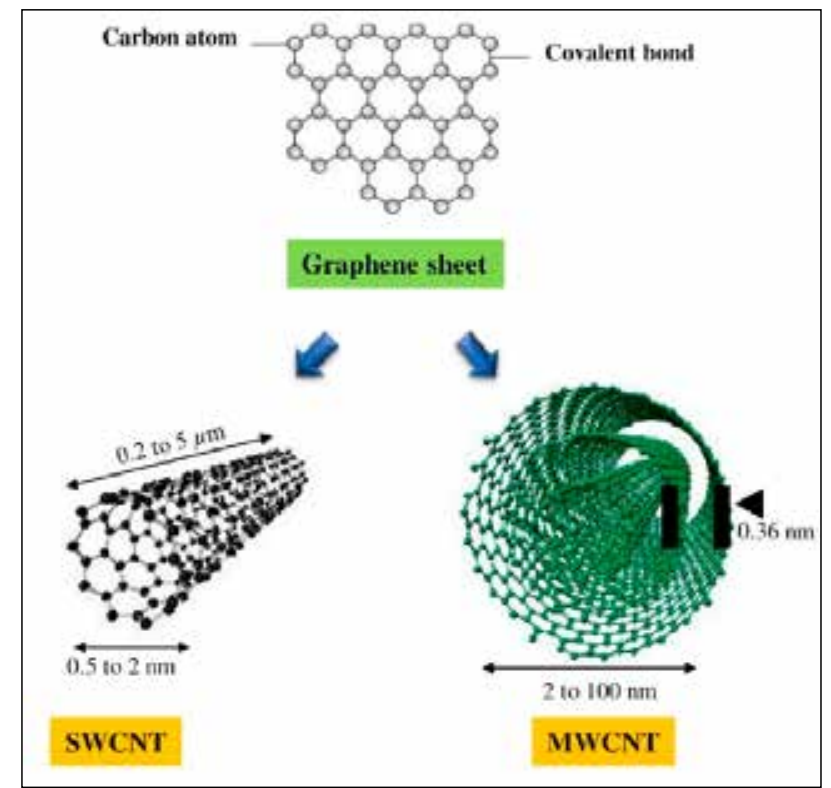

Fig. 26. The conceptual scheme representing general dimensions of the length and width of single walled carbon nanotubes (SWCNTs) and multi walled carbon nanotubes (MWCNTs) [131].
(MWCNTs) (Fig. 27) with different functional groups and analyzed them using gas chromatography (GC). Confirmation of functionalization was performed through fourier transform infrared (FTIR). The observed findings demonstrated that the MWCNTs with a larger surface area and higher crystallinity have a significant adsorption capacity for both benzene and toluene [132].

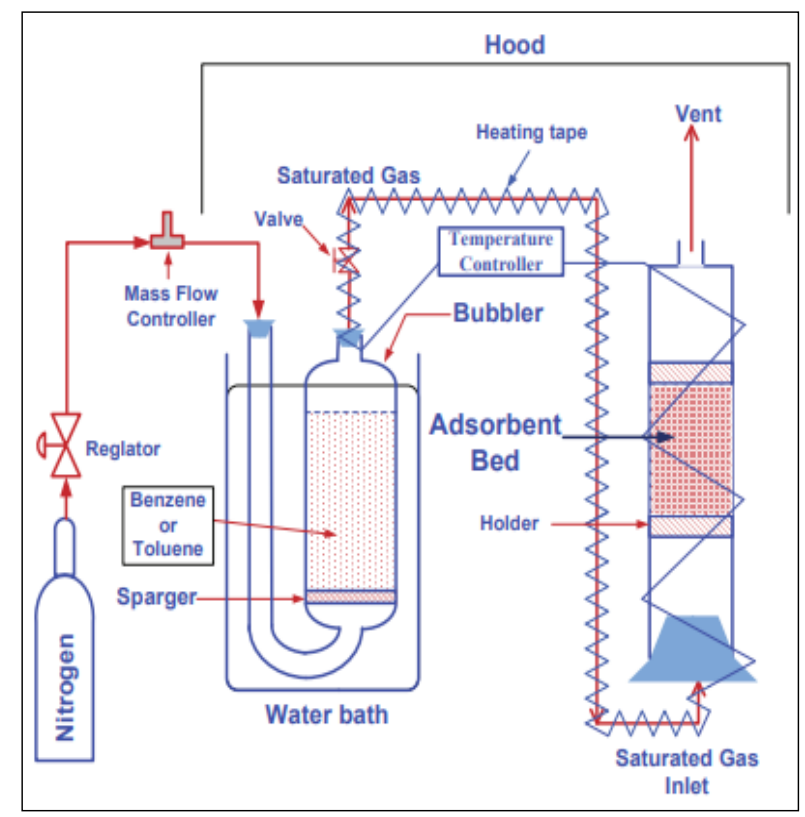

Fig. 27. Schematic diagram of experiment setup toward measurement of adsorption capacity of MWCNTs [132].

\section{Comparing of diriment sorbent for removal VOCs from waters/gas}

The removal procedure for VOCs from waters was compared by different analyzer such as GCMS,GC-FID, HS-GC-MS, GC-FID/ HPLC-UV, SWV and HPLC which was shown in Table 1.

Due to Table 1, the different sorbents and techniques compared as detection limit (LOD), recovery( R), relative standard deviation(RSD\%), adsorption/ desorption, temperature( $\mathrm{T})$ and absorption capacity(AC) in water samples. 
Table1. Determination and separation VOCs from water/gas by different sorbents and methods

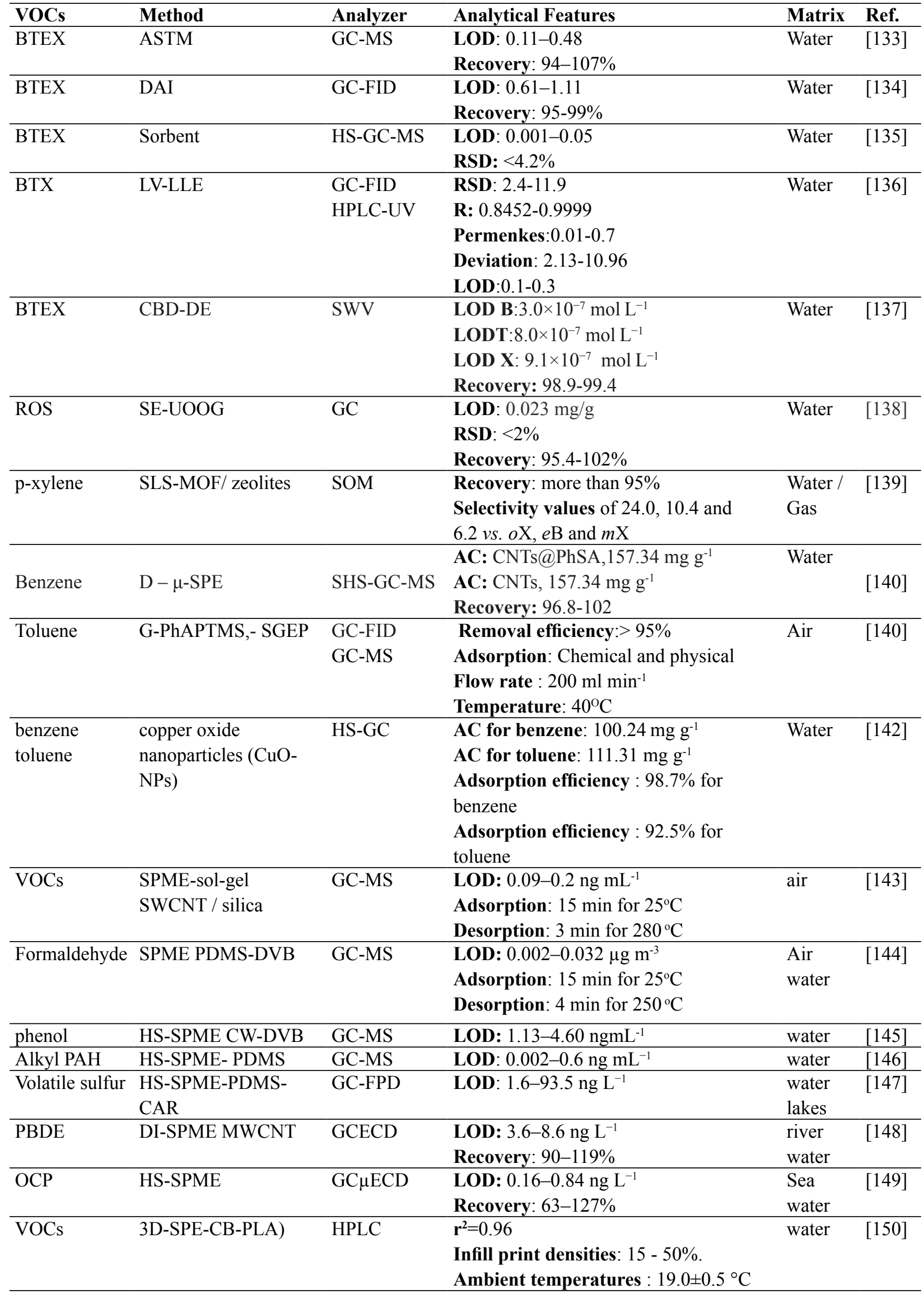


AC: Absorption Capacity

GC-MS: Gas chromatography mass spectrometry

GC-FID: Gas chromatography equipped with flame ionization detector

SWV: Square wave voltammetry

SHS-GC-MS: Head space gas chromatography mass spectrometry

GC: Gas Chromatography

SOM: Sized Organic Molecules

ROS: Residual organic solvent (ethanol, tetrahydrofuran, cyclohexane, n-heptane)

D- $\mu$-SPE: Dispersive micro solid phase extraction method

SLS: Solid liquid separation

SE-UOOG: Solvent extraction-Unconventional oil ore Gangues

CBD-DE: Cathodically pretreated boron doped diamond electrode

LV-LLE: Low volume liquid-liquid extraction

DAI: Direct aqueous injection

ASTM: ASTM D-5790 Purge and trap

G-PhAPTMS- SGEP: Functionalizing graphene with

N-Phenyl-3-aminopropyl trimethoxy -sorbent gas extraction

HS-GC: Headspace gas chromatograph

3D-SPE-CB-PLA: 3D printed solid-phase extraction carbon black modified polylactic acid (PLA)

OCP: Organo chlorine pesticides

PBDE: Polybrominated diphenyl ethers ACN: acetonitrile

BTEX: benzene, toluene, ethyl benzene, ortho-xylene and meta- and para-xylene

BTX: benzene, toluene and xylene

DAD: diode array detector

DI: direct immersion

ECD: electron capture detector

FID: flame ionization detector

FPD: flame photometric detector

FD: fluorescence detection

LOD: limit of detection $\left(\mu \mathrm{g} \mathrm{L}^{-1}\right)$

LOQ: limit of quantification $\left(\mu \mathrm{g} \mathrm{L}^{-1}\right)$

MA: microwave assisted

MAE: microwave assisted extraction

MW: multiwalled; PAHs: polycyclic aromatic hydrocarbons

PDMSAC: PDMS mixed with activated C

TSD: thermoionic specific detection

\section{Conclusions}

Through entering from different sources such as water, air and foods, the VOCs cause several diseases in humans. So, the environmental samples such as water, wastewater and air must be controlled and determined by applied methodologies. The human life depends on water future and elimination of pollutions such as VOCs in waters. By growing economy and increasing population, the main theme is water supplies without any contaminations. Quantity and quality of water must be checked daily and main parameters of waters should be controlled. So, the water, especially drinking water conservation is extremely important, and contaminations such as BTEX, VOCs and other organic pollutions in waters should be removed by new technologies. The technologies based on sorbents depend on water characteristics, affordability, acceptability and level of application. Every methodology for VOCs removal from waters have many advantages and disadvantages for water treatment. Therefore, the important parameters for any methodology such as speed, simplicity and selectivity must be studied. The vary methodology such as, solid phase extraction, liquid phase extraction, the adsorption/ desorption, the sole gel technology, RCO, CO and PCO have been used for VOCs removal from waters. In this review the recent technologies based on sorbents or catalysts are introduced for VOCs removal from water samples.

\section{Acknowledgement}

This review was supported by the Science and Research Branch, Islamic Azad University and Dr. Hamid Shirkhanloo in Research Institute of Petroleum Industry of Iran.

\section{References}

[1] K. Tzortzatou, E. Grigoropoulou, Catalytic oxidation of industrial organic solvent vapors, J. Environ. Sci. Health Part A, 45 (2010) 534-541.

[2] I. Rutkiewicz, W. Kujawski, J. Namieśnik, Pervaporation of volatile organohalogen compounds through polydimethylsiloxane membrane, Desalination, 264 (2010) 160164.

[3] W.S. Backer, WITHDRAWN: The impact of methyl tertiary-butyl ether (MTBE) on contaminated drinking water in organic 
blood chemistry, Elsevier. 2013.

[4] I. Levchuk, A. Bhatnagar, M. Sillanpää, Overview of technologies for removal of methyl tert-butyl ether (MTBE) from water, Sci. Total Environ., 476 (2014).415433.

[5] C. Perego, R. Bagatin, M. Tagliabue, R. Vignol, et al., Zeolites and related mesoporous materials for multi-talented environmental solutions, Micropor. Mesopor. Mater., 166 (2013) 37-49.

[6] S. Xia, X. Dong, Y. ZHU, W. Wei, F. Xiangli, W. Jin, Dehydration of ethyl acetate-water mixtures using PVA/ceramic composite pervaporation membrane, Sep. Purif. Technol., 77 (2011) 53-59.

[7] U. Hömmerich, R. Rautenbach, Design and optimization of combined pervaporation/ distillation processes for the production of MTBE, J. Membrane Sci., 146 (1998) 53-64.

[8] W. Kujawski, Application of pervaporation and vapor permeation in environmental protection, Polish J. Environ. Studies, 9 (2000)13-26.

[9] P. Sampranpiboon, R. Jiraratananon, D. Uttapap, X. Feng, RY. Huang., Pervaporation separation of ethyl butyrate and isopropanol with polyether block amide (PEBA) membranes, J. Membrane Sci., 173 (2000) 53-59.

[10] W. Yoshida, Y. Cohen, Removal of methyl tertbutyl ether from water by pervaporation using ceramic-supported polymer membranes, J. Membrane Sci., 229 (2004) 27-32.

[11] D. Zadaka-Amir, A. Nasser, S. Nir, YG. Mishael, Removal of methyl tertiary-butyl ether (MTBE) from water by polymerzeolite composites, Micropor. Mesopor. Mater., 151(2012) 216-222.

[12] K. Zhou, QG. Zhang, GL. Han, AM. Zhu, QL. Liu, Pervaporation of water-ethanol and methanol-MTBE mixtures using poly (vinyl alcohol)/cellulose acetate blended membranes, J. Membrane Sci., 448 (2013) 93-101.
[13] A. Kumar, BP. Singh, M. Punia, D. Singh, K. Kumar, VK. Jain, Assessment of indoor air concentrations of VOCs and their associated health risks in the library of Jawaharlal Nehru University, New Delhi, Environ. Sci. Pollut. Res., 21 (2014)2240-2248.

[14] P. Saxena, C. Ghosh, A review of assessment of benzene, toluene, ethylbenzene and xylene (BTEX) concentration in urban atmosphere of Delhi, Int. J. Phys. Sci., 7 (2012) 850-860.

[15] A.R. Schnatter, DC. Glass, G. Tang, RD. Irons, L. Rushton, Myelodysplastic syndrome and benzene exposure among petroleum workers: an international pooled analysis, J. Natl. Cancer Inst., 104 (2012) 1724-1737.

[16] T. Tunsaringkarn, W. Siriwong, A. Rungsiyothin, S. Nopparatbundit, Occupational exposure of gasoline station workers to BTEX compounds in Bangkok, Thailand, Int. J. Occup. Environ. Med., 3 (2012) 117-125.

[17] Cancer, I.A.f.R.o. Agents classified by the IARC Monographs. International Agency for Research on Cancer, pp1-109, 2014. http:// monographs.iarc.fr/ENG/Classification/ ClassificationsAlphaOrder.pdf

[18] S. Garte, E. Taioli, T. Popov, C. Bolognesi, P. Farmer, F. Merlo, Genetic susceptibility to benzene toxicity in humans, J. Toxicol. Environ. Health Part A, 71 (2008)1482-1489.

[19] C. Abbate, C. Giorgianni, F. Munao, R. Brecciaroli, Neurotoxicity induced by exposure to toluene, Int. Arch. Occup. Environ. Health, 64 (1993) 389-392.

[20] L. Ernstgård, E. Gullstrand, A. Löf, G. Johanson, Are women more sensitive than men to 2-propanol and m-xylene vapors, Occup. Environ. Med., 59 (2002) 759-767.

[21] GG. Bond, EA. McLaren, CL. Baldwin, RR. Cook, An update of mortality among chemical workers exposed to benzene, Occup. Environ. Med., 43 (1986) 685-691.

[22] MA. Midzenski, MA. McDiarmid, N. Rothman, K. Kolodner, Acute high dose exposure to benzene in shipyard workers. 
Am. J. Ind. Med., 22 (1992) 553-565.

[23] K. Murata, S. Araki, K. Yokoyama, T. Tanigawa, K. Yamashita, F. Okajima, T. Sakai, C. Matsunaga, K. Suwa, Cardiac autonomic dysfunction in rotogravure printers exposed to toluene in relation to peripheral nerve conduction, Ind. health, 31(1993) 79-90.

[24] JE. Cometto-Mu, WS. Cain, Relative sensitivity of the ocular trigeminal, nasal trigeminal and olfactory systems to airborne chemicals, Chem. Senses., 20 (1995) 191-198.

[25] E. Ahaghotu, RJ. Babu, A. Chatterjee, M. Singh, Effect of methyl substitution of benzene on the percutaneous absorption and skin irritation in hairless rats, Toxicol. lett., 159 (2005) 261-271.

[26] F. Doghieri, A. Nardella, GC. Sarti, C. Valentini, Pervaporation of methanol-MTBE mixtures through modified poly (phenylene oxide) membranes, J. Membrane Sci., 91(1994) 283291.

[27] L. Gales, A. Mendes, C. Costa, Removal of acetone, ethyl acetate and ethanol vapors from air using a hollow fiber PDMS membrane module, J. Membrane Sci., 197(2002)211-222.

[28] W. Kujawski, S. Krajewska, M. Kujawski, L. Gazagnes, A. Larbot, M. Persin, Pervaporation properties of fluoroalkylsilane (FAS) grafted ceramic membranes, Desalination., 205 (2007) 75-86.

[29] A. Urkiaga, N. Bolano, L. De Las Fuentes, Removal of micropollutants in aqueous streams by organophilic pervaporation, Desalination.,149 (2002) 55-60.

[30] J. Cheng, L. Li, Y. Li, Q. Wang, C. He, Fabrication of pillar [5] arene-polymer-functionalized cotton fibers as adsorbents for adsorption of organic pollutants in water and volatile organic compounds in air, Cellulose, 26 (2019) 32993312.

[31] V. Kumar, S. Kumar, KH. Kim, DC. Tsang, SS. Lee, Metal organic frameworks as potent treatment media for odorants and volatiles in air, Environ. Res. Lett., 168 (2019)336-356.

[32] S. KP Veerapandian, N. De Geyter, JM.
Giraudon, JF. Lamonier, R. Morent, The use of zeolites for VOCs abatement by combining non-thermal plasma, adsorption, and/or catalysis: a review, Catalysts, 9 (2019) 98.

[33] J. Hou, Z. Xia, S. Li, K. Zhou, N. Lu, Operation parameter optimization of a gas hydrate reservoir developed by cyclic hot water stimulation with a separated-zone horizontal well based on particle swarm algorithm, Energy J., 96 (2016) 581-591.

[34] MA. Campesi, CD. Luzi, GF. Barreto, OM. Martínez, Evaluation of an adsorption system to concentrate VOC in air streams prior to catalytic incineration, J. Environ. Manage., 154 (2015) 216-224.

[35] F. Chu, Y. Zheng, B. Wen, L. Zhou, J. Yan, Y. Chen, Adsorption of toluene with water on zeolitic imidazolate framework-8/graphene oxide hybrid nanocomposites in a humid atmospherem, RSC Adv., 8 (2018) 24262432.

[36] M. Mao, Y. Li, J. Hou, M. Zeng, X. Zhao. Extremely efficient full solar spectrum light driven thermocatalytic activity for the oxidation of VOCs on OMS-2 nanorod catalyst, Appl. Catal. B., 174 (2015) 496-503.

[37] W. Jianping, C. Yu, J. Xiaoqiang, C. Dongyan, Simultaneous removal of ethyl acetate and ethanol in air streams using a gas-liquidsolid three-phase flow airlift loop bioreactor, Chem. Eng. J., 106 (2005) 171-175.

[38] LM. Vane, FR. Alvarez, Full-scale vibrating pervaporation membrane unit: VOC removal from water and surfactant solutions, J. Membrane Sci., 202 (2002) 177-193.

[39] LM. Vane, FR. Alvarez, B. Mullins, Removal of methyl tert-butyl ether from water by pervaporation: bench-and pilot-scale evaluations, Environ. Sci. Technol., 35 (2001) 391-397.

[40] S. Zheng, C. Shen, M. Alunbate, J. Deng, L. Wang, Z. Han, H. Tang, Discovery of VOCcompliant TEOS sol and its application to $\mathrm{SiO}_{2}$ /novolac hybrid coatings, Prog. Org. 
Coat., 76 (2013) 425-431.

[41] D. Delimaris, T. Ioannides, VOC oxidation over $\mathrm{MnOx}-\mathrm{CeO}_{2}$ catalysts prepared by a combustion method, Appl. Catal. B., 84 (2008) 303-312.

[42] E. Gallego, JF. Perales, FJ. Roca, X. Guardino, Surface emission determination of volatile organic compounds (VOC) from a closed industrial waste landfill using a self-designed static flux chamber, Sci. Total Environ., 470 (2014) 587-599.

[43] HO. Karlsson, G. Trägårdh, Aroma compound recovery with pervaporation-feed flow effects, J. Membrane Sci., 81 (1993) 163171.

[44] T. Masuda, M. Takatsuka, BZ. Tang, T. Higashimura, Pervaporation of organic liquid-water mixtures through substituted polyacetylene membranes, J. Membrane Sci., 49 (1990) 69-83.

[45] HC. Park, NE. Ramaker, MH. Mulder, CA. Smolders, Separation of MTBE-methanol mixtures by pervaporation, Sep. Sci. Technol., 30 (1995) 419-433.

[46] Z. Qi, EL. Cussler, Microporous hollow fibers for gas absorption: I. Mass transfer in the liquid, J. Membrane Sci., 23 (1985) 321-332.

[47] M. Bhowmick, MJ. Semmens, Batch studies on a closed loop air stripping process, Water Res., 28 (1994) 2011-2019.

[48] MJ. Semmens, R. Qin, A. Zander. Using a microporous hollow-fiber membrane to separate VOCs from water, J. AM. Water Works ASS., 81 (1989) 162-167.

[49] AK. Zander, MJ. Semmens, RM. Narbaitz, Removing VOCs by membrane stripping. J. AM. Water Works ASS., 81 (1989) 76-81.

[50] K. Castro, AK. Zander, Membrane air-stripping: effects of pretreatment, J. AM. Water Works ASS., 87 (1995) 50-61.

[51] A. Das, I. Abou-Nemeh, S. Chandra, KK. Sirkar, Membrane-moderated stripping process for removing VOCs from water in a composite hollow fiber module, J. Membrane Sci., 148 (1998) 257-271.
[52] H. Mahmud, A. Kumar, Rm. Narbaitz, T. Matsuura, Membrane air stripping: a process for removal of organics from aqueous solutions. 1998.

[53] H. Mahmud, A. Kumar, RM. Narbaitz, T. Matsuura, A study of mass transfer in the membrane air-stripping process using microporous polyproplylene hollow fibers, J. Membrane Sci., 179 (2000) 29-41.

[54] H. Mahmud, A. Kumar, RM. Narbaitz, T. Matsuura, Mass transport in the membrane air-stripping process using microporous polypropylene hollow fibers: effect of toluene in aqueous feed, $\mathrm{J}$. Membrane Sci., 209 (2002) 207-219.

[55] A. Malek, K. Li, WK. Teo, Modeling of microporous hollow fiber membrane modules operated under partially wetted conditions, Ind. Eng. Chem. Res., 36 (1997) 784-793.

[56] A. Gabelman, ST. Hwang, Hollow fiber membrane contactors, J. Membrane Sci., 159 (1999) 61-106.

[57] M. Jabłońska, A. Król, E. Kukulska-Zając, K. Tarach, V. Girman, L. Chmielarz, K. GóraMarek, Zeolites Y modified with palladium as effective catalysts for low-temperature methanol incineration, Appl. Catal. B., 166 (2015) 353-365.

[58] SC. Kim, WG. Shim, Properties and performance of Pd based catalysts for catalytic oxidation of volatile organic compounds, Appl. Catal. B., 92 (2009) 429-436.

[59] ME. Jenkin, SM. Saunders, RG. Derwent, MJ. Pilling, Development of a reduced speciated VOC degradation mechanism for use in ozone models, Atmos. Environ., 36 (2002) 4725-4734.

[60] JY. Jeon, HY. Kim, SL. Woo, Mechanistic study on the SCR of NO by C3H6 over Pt/V/MCM-41. Appl. Catal. B., 44 (2003) 301-310.

[61] DP. Debecker, B. Farin, EM. Gaigneaux, C. Sanchez, C. Sassoye, Total oxidation of propane with a nano-RuO2/TiO2 catalyst, Appl. Catal. A-gen., 481 (2014) 11-18.

[62] MP. Pina, S. Irusta, M. Menéndez, J. Santamaria, R. Hughes, N. Boag, Combustion of volatile organic compounds over platinum-based catalytic membranes, Ind. Eng. Chem. Res., 36 (1997) 4557-4566.

[63] HJ. Joung, JH. Kim, JS. Oh, DW You, HO. Park, 
KW. Jung, Catalytic oxidation of VOCs over CNT-supported platinum nanoparticles, Appl. Surf. Sci., 290 (2014) 267-273.

[64] Z. Abdelouahab-Reddam, R. El Mail, F. Coloma, A. Sepúlveda-Escribano, Platinum supported on highly-dispersed ceria on activated carbon for the total oxidation of VOCs, Appl. Catal. A-Gen., 494 (2015) 87-94.

[65] M. Konsolakis, SA. Carabineiro, PB. Tavares, JL. Figueiredo, Redox properties and VOC oxidation activity of $\mathrm{Cu}$ catalysts supported on $\mathrm{Ce} 1-$ xSmxO 0 mixed oxides, J. Hazard. Mater., 261 (2013) 512-521.

[66] M. Piumetti, D. Fino, N. Russo, Mesoporous manganese oxides prepared by solution combustion synthesis as catalysts for the total oxidation of VOCs, Appl. Catal. B., 163 (2015) 277-287.

[67] S. Scirè, RM. Riccobene, C. Crisafulli, Ceria supported group IB metal catalysts for the combustion of volatile organic compounds and the preferential oxidation of $\mathrm{CO}$, Appl. Catal. B., 101 (2010) 109-117.

[68] SH. Teimoori, AH. Hassani, M. Panaahie, Extraction and determination of benzene from waters and wastewater samples based on functionalized carbon nanotubes by static head space gas chromatography mass spectrometry Anal. Method Environ. Chem. J., 3 (2020) 17-26

[69] V. Kumar, YS. Lee, JW Shin, KH. Kim, D. Kukkar, YF. Tsang, Potential applications of graphenebased nanomaterials as adsorbent for removal of volatile organic compounds Vanish Kumara,1, Yoon-Seo Lee, Environ. Int., 135 (2020) 105356.

[70] DR. Dreyer, S. Park, CW. Bielawski, RS. Ruoff. The chemistry of GO, Chem. Soc. Rev., 39 (2010) 228-40.

[71] G. Ruess, Über das Graphitoxyhydroxyd (Graphitoxyd). Monatshe. Chem. Verwandte Teile Wissenschaft., 76 (1974) 381-417.

[72] W. Scholz, HP. Boehm, Untersuchungen am graphitoxid. VI. Betrachtungen zur struktur des graphitoxids, Z Anorg Allg Chem., 369 (1969) 327-340.

[73] T. Szabó, O. Berkesi, P. Forgó, K. Josepovits,
Y. Sanakis, D. Petridis, I. Dékány, Evolution of surface functional groups in a series of progressively oxidized graphite oxides, Chem. Mater., 18 (2006) 2740-2749.

[74] F. Chu, Y. Zheng, B. Wen, L. Zhou, J. Yan, Y. Chen, Adsorption of toluene with water on zeolitic imidazolate framework-8/graphene oxide hybrid nanocomposites in a humi atmosphere, RSC Adv., 8 (2018) 2426-2432.

[75] L. Yu, L. Wang, W. Xu, L. Chen, M. Fu, J. Wu, D. Ye. Adsorption of VOCs on reduced graphene oxide, J. Environ. Sci., 67 (2018) 171-8.

[76] B. Szczęśniak, J. Choma, m. Jaroniec, Effect of graphene oxide on the adsorption properties of ordered mesoporous carbons toward H2, C6H6, CH4 and CO2, Micropor. Mesopor. Mater., 261 (2018) 105-110.

[77] B. Szczęśniak, L. Osuchowski, J. Choma, M. Jaroniec. Highly porous carbons obtained by activation of polypyrrole/reduced graphene oxide as effective adsorbents for $\mathrm{CO}_{2}, \mathrm{H} 2$ and $\mathrm{C}_{6} \mathrm{H}_{6}, \mathrm{~J}$. Porous Mater., 25 (2018) 621-627.

[78] GQ. Liu, MX. Wan, ZH. Huang, FY. Kang, Preparation of graphene/metal-organic composites and their adsorption performance for benzene and ethanol, New Carbon Mater., 30 (2015) 566-571

[79] JM. Kim, JH. Kim, CY. Lee, DW. Jerng, HS. Ahn, Toluene and acetaldehyde removal from air on to graphene-based adsorbents with microsized pores, J. Hazard. Mater., 344 (2018) 458-65.

[80] L. Wu, 1. Zhang, T. Meng, F. Yu, J. Chen, J. $\mathrm{Ma}$, Facile synthesis of 3D amino-functional graphene-sponge composites decorated by graphene nanodots with enhanced removal of indoor formaldehyde, Aerosol Air Qual Res., 15 (2015) 1028-34.

[81] V. Kumar, YS. Lee, JW. Shin, KH. Kim,D. Kukkar, YF. Tsang, Potential applications of graphenebased nanomaterials as adsorbent for removal of volatile organic compounds, Environ. Int., 135 (2020) 105356.

[82] ST. Lim, JH. Kim, CY. Lee, S. Koo, DW. Jerng, S. Wongwises, HS. Ahn, Mesoporous graphene adsorbents for the removal of toluene and xylene 
at various concentrations and its reusability, Sci. Rep., 9 (2019) 1-12.

[83] TK. Tseng, YS. Lin, YJ. Chen, H. Chu, A review of photocatalysts prepared by sol-gel method for VOCs removal, Int. J. Mol. Sci., 11 (2010) 23362361.

[84] U. Schubert, Catalysts made of organic-inorganic hybrid materials, New J. Chem., 18 (1994) 10491058.

[85] J. Blum, A. Rosenfeld, F. Gelman, H. Schumann, D. Avnir, Hydrogenation and dehalogenation of aryl chlorides and fluorides by the sol-gel entrapped $\mathrm{RhCl3}-\mathrm{Aliquat} 336$ ion pair catalyst, J. Mol. Catal. A Chem., 146 (1999) 117-122.

[86] P. Banet, C. Cantau, C. Rivron, TH. Tran-Thi, Nano-porous sponges and proven chemical reactions for the trapping and sensing of halogenated gaseous compounds, Actual. Chim., (2009) 30-35.

[87] J. Lin, CW. Brown, Sol-gel glass as a matrix for chemical and biochemical sensing. Trac-Trend Anal. Chem., 16 (1997) 200-211.

[88] R. Gvishi, U. Narang, G. Ruland, DN. Kumar, PN. Prasad, Novel, Organically Doped, Sol-GelDerived Materials for Photonics: Multiphasic Nanostructured Composite Monoliths and Optical Fibers, Appl. Organomet. Chem., 11 (1997) 107127.

[89] B. Dunn, GC. Farrington, B. Katz, Sol-gel approaches for solid electrolytes and electrode materials, Solid State Ion., 70 (1994) 3-10.

[90] D. Levy, L. Esquivias, Sol-gel processing of optical and electrooptical materials, Adv. Mater., 7 (1995) 120-129.

[91] B. Dunn, JI. Zink, Optical properties of sol-gel glasses doped with organic molecules. J. Mater. Chem., 1 (1991) 903-913.

[92] D. Levy, Recent applications of photochromic sol-gel materials. molecular crystals and liquid crystals science and technology, section A, Mol. Cryst. Liq. Cryst., 297 (1997) 31-39.

[93] G. Xomeritakis, CY. Tsai, YB. Jiang, CJ. Brinker, Tubular ceramic-supported sol-gel silica-based membranes for flue gas carbon dioxide capture and sequestration, J. Membr. Sci., 341 (2009) 30-
36.

[94] Z. Zeng, W. Qiu, M. Yang, X. Wei, Z. Huang, F. Li, Solid-phase microextraction of monocyclic aromatic amines using novel fibers coated with crown ether, J. Chromatogr. A., 934 (2001) 51-57.

[95] MR. Hoffmann, ST. Martin, W. Choi, DW. Bahnemann, Environmental applications of semiconductor photocatalysis, Chem. Rev., 95 (1995) 69-96.

[96] L. Cao, Z. Gao, SL. Suib, TN. Obee, SO. Hay, JD. Freihaut, Photocatalytic oxidation of toluene on nanoscale $\mathrm{TiO} 2$ catalysts: studies of deactivation and regeneration, J. Catal., 196 (2000) 253-261.

[97] S. Yamazaki, H. Abe, T. Tanimura, Y. Yamasaki, K. Kanaori, K. Tajima, Effect of thermal treatment on the photocatalytic degradation of ethylene, trichloroethylene, and chloroform, Res. Chem. Intermed., 35 (2009) 91-101.

[98] WH. Ching, M. Leung, DY. Leung, Solar photocatalytic degradation of gaseous formaldehyde by sol-gel $\mathrm{TiO} 2$ thin film for enhancement of indoor air quality, Sol. Energy., 77 (2004) 129-135.

[99] BY. Lee, SW. Kim, SC. Lee, HH. Lee, SJ. Choung, Photocatalytic decomposition of gaseous formaldehyde using $\mathrm{TiO}_{2}, \mathrm{SiO}_{2}-\mathrm{TiO}_{2}$ and $\mathrm{Pt}-$ $\mathrm{TiO}_{2}$, Int. J. Photoenergy, 5 (2002) 463920.

[100] N. Parvizi, N. Rahemi, S. Allahyari, M. Tasbihi, Plasma-catalytic degradation of BTX over ternary perovskite-type La1-x (Co, $\mathrm{Zn}, \mathrm{Mg}, \mathrm{Ba})$ xMnO3 nanocatalysts, J. Ind. Eng. Chem., 84 (2020) 167178.

[101] DP. Debecker, R. Delaigle, K. Bouchmella, P. Eloy, EM. Gaigneaux, PH. Mutin, Total oxidation of benzene and chlorobenzene with $\mathrm{MoO} 3$-and WO3-promoted V2O5/TiO2 catalysts prepared by a nonhydrolytic sol-gel route, Catal. Today, 157 (2010) 125-130.

[102] A. Sarafraz-Yazdi, A. Amiri, G. Rounaghi, HE. Hosseini, A novel solid-phase microextraction using coated fiber based sol-gel technique using poly (ethylene glycol) grafted multi-walled carbon nanotubes for determination of benzene, toluene, ethylbenzene and o-xylene in water samples with gas chromatography-flam ionization detector, J. 
Chromatogr. A, 1218 (2011) 5757-5764.

[103] T. Uragami, H. Yamada, T. Miyata, Removal of dilute volatile organic compounds in water through graft copolymer membranes consisting of poly (alkylmethacrylate) and poly (dimethylsiloxane) by pervaporation and their membrane morphology, J. Membr. Sci., 187 (2001) 255-269.

[104] T. Uragami, T. Ohshima, T. Miyata, Removal of benzene from an aqueous solution of dilute benzene by various cross-linked poly (dimethylsiloxane) membranes during pervaporation, Macromolecules, 36 (2003) 9430-9436.

[105] T. Ohshima, T. Miyata, T. Uragami, H. Berghmens, Cross-linked smart poly (dimethylsiloxane) membranes for removal of volatile organic compounds in water, J. Mol. Struc., 739 (2005) 47-55.

[106] T. Ohshima, Y. Kogami, T. Miyata, T. Uragami, Pervaporation characteristics of cross-linked poly (dimethylsiloxane) membranes for removal of various volatile organic compounds from water, J. Membrane Sci., 260 (2005) 156-163.

[107] H. Zhen, SM. Jang, WK. Teo, K. Li, Modified silicone-PVDF composite hollow fiber membrane preparation and its application in VOC separation, J. Appl. Polym. Sci., 99 (2006) 2497-2503.

[108] H. Wu, L. Liu, F. Pan, C. Hu, Z. Jiang, Pervaporative removal of benzene from aqueous solution through supramolecule calixarene filled PDMS composite membranes, Sep. Purif. Technol., 51 (2006) 352-358.

[109] S. Chovau, A. Dobrak, A. Figoli, F. Galiano, S. Simone, E. Drioli, SK. Sikdar, B. Van der Bruggen, Pervaporation performance of unfilled and filled PDMS membranes and novel SBS membranes for the removal of toluene from diluted aqueous solutions, Chem. Eng. J., 159 (2010) 37-46.

[110] J. Xu, A. Ito, Removal of VOC from water by pervaporation with hollow-fiber silicone rubber membrane module, Desalination Water Treat., 17 (2010) 135-42.

[111] T. Uragami, I. Sumida, T. Miyata, T. Shiraiwa, H. Tamura, T. Yajima, Pervaporation characteristics in removal of benzene from water through polystyrene-poly (dimethylsiloxane) IPN membranes, Mater. Sci. Appl., 2 (2011)169.

[112] T. Uragami, Y. Matsuoka, T. Miyata. Removal of dilute benzene in water through ionic liquid/poly (vinyl chloride) membranes by pervaporation, J. Membrane Sci. Res., 2 (2016) 20-5.

[113] J. Kujawa, S. Al-Gharabli, W. Kujawski, K. Knozowska. Molecular grafting of fluorinated and nonfluorinated alkylsiloxanes on various ceramic membrane surfaces for the removal of volatile organic compounds applying vacuum membrane distillation, ACS Appl. Mater. Inter., 9 (2017) 6571-90.

[114] Z. Zhang, Z. Jiang, W. Shangguan. Lowtemperature catalysis for VOCs removal in technology and application: A state-of-theart review, Catal. Today, 264 (2016) 270-8.

[115] X. Liu, J. Zeng, W. Shi, J. Wang, T. Zhu, Y. Chen. Catalytic oxidation of benzene over ruthenium-cobalt bimetallic catalysts and study of its mechanism, Catal, Sci, Technol., 7 (2017) 213-21.

[116] M. Zhang, W. Li, X. Wu, F. Zhao, D. Wang, X, Zha, S. Li, H. Liu, Y. Chen. Lowtemperature catalytic oxidation of benzene over nanocrystalline $\mathrm{Cu}-\mathrm{Mn}$ composite oxides by facile sol-gel synthesis, New J. Chem., 44 (2020) 2442-51.

[117] P. Marín, FV. Díez, S. Ordóñez. A new method for controlling the ignition state of a regenerative combustor using a heat storage device, Appl. Energy, 116 (2014) 322-32.

[118] S. Hoseini, N. Rahemi, S. Allahyari, M. Tasbihi. Application of plasma technology in the removal of volatile organic compounds (BTX) using manganese oxide nano-catalysts synthesized from spent batteries, J. Clean. Prod., 232 (2019) 1134-47. 
[119] V. Georgiev. Ozone Assisted Low Temperature Catalytic Benzene Oxidation over Al2O3, $\mathrm{SiO} 2, \mathrm{AlOOH}$ Supported Ni/Pd Catalytic, Int. J. Chem. Mater. Eng., 14 (2020) 168-73.

[120] J. Zhang, Y. Hu, J. Qin, Z. Yang, M. Fu. $\mathrm{TiO}_{2}-$ UiO-66- $\mathrm{NH}_{2}$ nanocomposites as efficient photocatalysts for the oxidation of VOCs, Chem. Eng. J., 385 (2020) 123814.

[121] J. Ji, Y. Xu, H. Huang, M. He, S. Liu, G. Liu, R. Xie, Q. Feng, Y. Shu, Y. Zhan, R. Fang. Mesoporous $\mathrm{TiO}_{2}$ under VUV irradiation: Enhanced photocatalytic oxidation for VOCs degradation at room temperature, Chem. Eng. J., 327 (2017) 490-9.

[122] H. Huang, G. Liu, Y. Zhan, Y. Xu, Lu H, H. Huang, Q. Feng, M. Wu. Photocatalytic oxidation of gaseous benzene under VUV irradiation over $\mathrm{TiO}_{2}$ /zeolites catalysts, Catal. Today, 281 (2017) 649-55.

[123] P. Fu, P. Zhang, J. Li. Photocatalytic degradation of low concentration formaldehyde and simultaneous elimination of ozone by-product using palladium modified $\mathrm{TiO}_{2}$ films under UV irradiation. Appl. Catal. B: Environ., 105 (2011) 220-8.

[124] E. Rezaei, J. Soltan, N. Chen. Catalytic oxidation of toluene by ozone over alumina supported manganese oxides. Effect of catalyst loading, Appl. Catal. B: Environ., 136 (2013) 239-47.

[125] Y. Shu, M. He, J. Ji, H. Huang, S. Liu, DY. Leung. Synergetic degradation of VOCs by vacuum ultraviolet photolysis and catalytic ozonation over Mn-xCe/ZSM-5, J. Hazard. Mater., 364 (2019) 770-9.

[126] E. Rezaei, J. Soltan. Low temperature oxidation of toluene by ozone over $\mathrm{MnOx} /$ $\gamma$-alumina and MnOx/MCM-41 catalysts, Chem. Eng. j., 198 (2012) 482-90.

[127] AM. Vandenbroucke, R. Morent, N. De Geyter, C. Leys. Non-thermal plasmas for non-catalytic and catalytic VOC abatement, J. Hazard. Mater., 195 (2011) 30-54.

[128] HH. Kim, Y. Teramoto, N. Negishi, A. Ogata. A multidisciplinary approach to understand the interactions of nonthermal plasma and catalyst: A review, Catal. Today, 256 (2015) 13-22.

[129] H. Guo, X. Liu, H. Hojo, X. Yao, H. Einaga, W. Shangguan. Removal of benzene by nonthermal plasma catalysis over manganese oxides through a facile synthesis method, Environ. Sci. Pollut. Res., 26 (2019) 823747.

[130] N. Jiang, J. Hu, J. Li, K. Shang, N. Lu, Y. Wu. Plasma-catalytic degradation of benzene over $\mathrm{Ag}-\mathrm{Ce}$ bimetallic oxide catalysts using hybrid surface/packed-bed discharge plasmas, Appl. Catal. B: Environ., 184 (2016) 355-63.

[131] DK. Patel, HB. Kim, SD. Dutta, K. Ganguly, KT. Lim. Carbon nanotubes-based nanomaterials and their agricultural and biotechnological applications, Mater., 13 (2020) 1679.

[132] F. Pourfayaz, S. Boroun, J. Babaei, B. Ebrahimi Hoseinzadeh. An evaluation of the adsorption potential of MWCNTs for benzene and toluene removal, Int. J. Nanosci. Nanotechnol., 10 (2014) 27-34.

[133] LH. Keith, H. Lawrence, HJ. Brass, DJ. Sullivan, JA. Boiani, KT. Alben, An introduction to the national environmental methods index, Environ. Sci. Technol., 6 (2005) 173A-176A.

[134] R. Kubinec, J. Adamuščin, H. Jurdáková, M. Foltin, I. Ostrovský, A. Kraus, L. Soják, Gas chromatographic determination of benzene, toluene, ethylbenzene and xylenes using flame ionization detector in water samples with direct aqueous injection up to $250 \mu \mathrm{l}$, J. Chromatogr. A, 1084 (2005) 90-4.

[135] V. López Grimau, MC. Gutiérrez Bouzán, J. Griera, JM. Guadayol Cunill. Determination of non halogenated solvents in industrial wastewater using solid phase microextraction (SPME) and GC-MS, Latin Am. Appl. Res., 36 (2006) 49-55.

[136] R. Yusiasih, R. Marvalosha, SD. Suci, E. Yuliani, MM. Pitoi, Low volume liquid-liquid 
extraction for the determination of benzene, toluene, and xylene in water by GC-FID and HPLC-UV, IOP Conf. Ser.: Earth Environ. Sci., 277 (2019) 012019.

[137] G. Garcia de Freitas Junior, TM. Florêncio, RJ.Mendonça, GR. Salazar-Banda, Rt. Oliveira, Simultaneous Voltammetric Determination of Benzene, Toluene and Xylenes (BTX) in Water Using a Cathodically Pre-Treated Boron-Doped Diamond Electrode, Electroanal., 31 (2019) 554-559.

[138] X. Li, Z. Jia, J. Wang, H. Sui, L. He, OA.Volodin, Detection of Residual Solvent in Solvent-Extracted Unconventional Oil Ore Gangues. J. Eng. Thermophys., 28 (2019) 499-506.

[139] N. Sun, SQ. Wang, R. Zou ,WG. Cui,A Zhang, T. Zhang, Q. Li, ZZ. Zhuang, YH. Zhang,J. Xu, MJ. Zaworotko, Benchmark selectivity p-xylene separation by a nonporous molecular solid through liquid or vapor extraction, Chem. sci., 10 (2019) 88508854.

[140] S. Teimoori, AH.Hassani, M. Panaahie, The Extraction and determination of benzene from waters and wastewater samples based on functionalized carbon nanotubes by static head space gas chromatography mass spectrometry, Anal. Method Environ. Chem. J., 3 (2020) 17-26.

[141] MB. Hosseinabadi, AF. Zarandi, Functionalized graphene-trimethoxyphenyl silane for toluene removal from workplace air by sorbent gas extraction method, Anal. Method. Environ. Chem. J., 2 (2019) 45-54.

[142] L. Mohammadi, E. Bazrafshan, M. Noroozifar, A. Ansari-Moghaddam, F. Barahuie, D. Balarak, Adsorptive removal of Benzene and Toluene from aqueous environments by cupric oxide nanoparticles: kinetics and isotherm studies, J. Chem., 2017 (2017) 2069519.

[143] SG. Attari, A. Bahrami, FG. Shahna, M. Heidari,
Solid-phase microextraction fiber development for sampling and analysis of volatile organohalogen compounds in air, J. Environ. Health Sci. Eng., 12 (2014) 123-130.

[144] C. Nerın, MR. Philo, J. Salafranca, L.Castle, Determination of bisphenol-type contaminants from food packaging materials in aqueous foods by solid-phase microextraction-high-performance liquid chromatography, J. Chromatogr., 963 (2002) 375-380.

[145]FJ. Conde, Am. Afonso, V.González, JH. Ayala, Optimization of an analytical methodology for the determination of alkyl-and methoxy-phenolic compounds by HS-SPME in biomass smoke, Anal. Bioanal. chem., 385 (2006) 1162-1171.

[146] SB.Hawthorne, CB. Grabanski, DJ. Miller, JP. Kreitinger, Solid-phase microextraction measurement of parent and alkyl polycyclic aromatic hydrocarbons in milliliter sediment pore water samples and determination of K DOC values, Environ. Sci. Technol., 39 (2005) 27952803.

[147] X. Lu, C.Fan, J. Shang, J. Deng, H. Yin, Headspace solid-phase microextraction for the determination of volatile sulfur compounds in odorous hyper-eutrophic freshwater lakes using gas chromatography with flame photometric detection, Microchem. J., 104 (2012) 26-32.

[148] JX. Wang, DQ. Jiang, ZY. Gu, XP.Yan, Multiwalled carbon nanotubes coated fibers for solid-phase microextraction of polybrominated diphenyl ethers in water and milk samples before gas chromatography with electron-capture detection, J. Chromatogr. A, 1137 (2006) 8-14.

[149]MH. Banitaba, AA. Mohammadi, SS. Davarani, A. Mehdinia, Preparation and evaluation of a novel solid-phase microextraction fiber based on poly(3,4-ethylenedioxythiophene) for the analysis of OCPs in water, Anal. Methods, 3 (2011) 2061-2067.

[150] LA. Lagalante, AJ. Lagalante,AF. Lagalante. 3D printed solid-phase extraction sorbents for removal of volatile organic compounds from water, J. Water Process Eng., 35 (2020)101194. 